\title{
Small Molecules as Inhibitors of PCSK9: Current Status and Future
}

\section{Challenges}

Shengtao $\mathrm{Xu}^{\mathrm{a}, 1}$, Shanshan $\mathrm{Luo}^{\mathrm{b}, 1}$, Zheying $\mathrm{Zhu}^{\mathrm{c}}$, Jinyi $\mathrm{Xu}^{\mathrm{a},{ }^{*}}$


Pharmaceutical University, 24 Tong Jia Xiang, Nanjing 210009, P. R. China

${ }^{\mathrm{b}}$ Key Laboratory of Cardiovascular \& Cerebrovascular Medicine, School of Pharmacy, Nanjing Medical University, 101 Longmian Avenue, Nanjing 211166, P.R. China

'Division of Molecular Therapeutics \& Formulation, School of Pharmacy, The University of Nottingham, University Park Campus, Nottingham NG7 2RD, UK

Corresponding author: Xu, J. (jinyixu@china.com)

${ }^{1}$ Authors contributed equally.

\section{Abbreviations:}

AMPK, adenosine 5'-monophosphate activated protein kinase; BBR, berberine; BET, bromodomain and extra-terminal; BRDs, bromodomains; CES1, carboxylesterase 1; CETP, cholesteryl ester transfer protein; CRISPR, clustered regularly interspaced short palindromic repeats; CVD, cardiovascular disease; EGF(A), epidermal growth factor A; EKO, exploring key orientations; FoxO3a, forkhead box O3a; GOF, gain-offunction; HFNAPS, highly functionalized nucleic acid polymers; HMG-CoA, 3hydroxy-3-methylglutaryl-coenzyme A; HNF-1 $\alpha$, hepatocyte nuclear factor $1 \alpha$; HS, heparan sulfate; HSPGs, heparin sulfate proteoglycans; HTS, high-throughput screening; LDL-C, low-density lipoprotein-cholesterol; LDLRs, low-density lipoprotein receptors; LOF, loss-of-function; mAbs, monoclonal antibodies; MW, molecule weight; NARC1, neural apoptosis-regulated convertase 1; NUTs, nutritional compounds; PCSK9, proprotein convertase subtilisin/kexin type 9; PDB, protein data bank; PPI, protein-protein interaction; PROTAC, proteolysis-targeting chimera; Q3G, quercetin-3-glucoside; qPCR, quantitative polymerase chain reaction; SAR, structure 
activity relationship; siRNA, small interfering RNA; SPR, surface plasmon resonance; SREBP-2, sterol regulatory element binding protein-2; TC, total cholesterol; TR-FRET, time-resolved fluorescence resonance energy transfer; TRIB1, tribbles homolog 1; XZK, xuezhikang.

\begin{abstract}
Proprotein convertase subtilisin/kexin type 9 (PCSK9) plays an important role in regulating lipoprotein metabolism by binding to low-density lipoprotein receptors (LDLRs), leading to their degradation. LDL cholesterol (LDL-C) lowering drugs that operate through the inhibition of PCSK9 are being pursued for the management of hypercholesterolemia and reducing its associated atherosclerotic cardiovascular disease (CVD) risk. Two PCSK9-blocking monoclonal antibodies (mAbs), alirocumab and evolocumab, were approved in 2015. However, the high costs of PCSK9 antibody drugs impede their prior authorization practices and reduce their long-term adherence. Given the potential of small-molecule drugs, the development of small-molecule PCSK9 inhibitors has attracted considerable attention. This article provides an overview of the recent development of small-molecule PCSK9 inhibitors disclosed in the literature and patent applications, and different approaches that have been pursued to modulate the functional activity of PCSK9 using small molecules are described. Challenges and potential strategies in developing small-molecule PCSK9 inhibitors are also discussed.
\end{abstract}

\title{
Keywords
}

PCSK9 protein, inhibitor, small-molecule, LDL-C, hypercholesterolemia, natural products, patent

\section{Contents}

1. Introduction

2. Background

2.1. Biogenesis and structure of PCSK9 


\subsection{Physiological role of PCSK9}

2.3. Approaches to PCSK9 inhibition

3. Small-molecule PCSK9 inhibitors reported in scientific journals

3.1. Blocking the ribosome: from R-IMPP to PF-06815345

3.2. Heparan sulfate mimetics

3.3. CB_36 from in silico screening

3.4. Imidazole-based minimalist peptidomimetic

3.5. Discovery of semirigid scaffold using Exploring Key Orientations

3.6. Natural products

3.6.1. Berberine

3.6.2. CVI-LM001 from corydaline

3.6.3. Curcumin

3.6.4. Lignans

3.6.5. Moracin C

3.6.6. Polydatin

3.6.7. Tanshinone IIA

3.6.8. Aromatic compounds from Sparassis crispa

3.6.9. Flavonoids and flavanones

3.6.10. Other extracts from natural products

4. Small-molecule PCSK9 inhibitors reported in patents

4.1. Small molecules targeting the PCSK9/LDLR PPI

4.2. Small molecules inhibiting PCSK9 expression

4.3. Additional patents

5. Potential strategies for the design of small molecules

5.1. Another binding site on PCSK9 for the design of small-molecule inhibitors

5.2. Aptamers

5.3. Proteolysis-targeting chimera technology

5.4. Targeting the signal transduction cascade

6. Summary and future directions 


\section{Introduction}

Cardiovascular disease (CVD) is the leading cause of mortality worldwide despite advances in lifestyle and the available of various cardiovascular drugs.[1] Hypercholesterolemia has long been considered as an independent risk factor for CVD, and lowering low-density lipoprotein cholesterol (LDL-C) has been shown to reduce cardiovascular risk in clinical trials.[2] Several agents have been widely applied for reducing LDL-C levels in the treatment of hypercholesterolemia, including statins, ezetimibe, niacin, and bile acid sequestrates.[3] To date, 3-hydroxy-3-methylglutarylcoenzyme A (HMG-CoA) reductase inhibitors (statins) have been widely regarded as the first line of pharmacological treatment for lowering LDL-C, reducing risk of primary and secondary cardiovascular events.[4] Despite the successful application of statins alone or in combination with other lipid-lowering drugs, residual risk persists in a large portion of statin-treated patients $(\sim 25 \%)$ who fail to attain desirable LDL-C levels with the maximally tolerated statin therapy[5] or are intolerant to statins owing to various side effects such as muscle symptoms, headache, sleep disorder, rash, arthritis, etc.[6] Thus, safer and more effective nonstatin therapies for the treatment of dyslipidemia to reduce cardiovascular risk are needed.

PCSK9 is a recently identified but well-validated novel drug target that lowers LDLC levels for hypercholesterolemia treatment.[7] This protein plays an important role in regulating the degradation of hepatic low-density lipoprotein receptors (LDLRs), thereby increasing circulating LDL-C levels.[8] Various therapies have been designed to inhibit PCSK9 and consequently inhibit LDLR degradation.[9] In 2015, two fully human monoclonal antibodies (mAbs), alirocumab[10] and evolocumab,[11] were approved as PCSK9 inhibitors. They are efficacious, well tolerated, and have no obvious side effects.[12, 13] Recent clinical data of evolocumab have shown a reduction in cardiovascular events by $15 \%$ after a median treatment of 2.2 years, confirming the clinical benefit of PCSK9 inhibition as a drug target.[11]

The most studied and clinically approved approach to inhibit PCSK9 is the use of $\mathrm{mAbs}$, and comprehensive reviews have summarized the development process, safety and tolerability of anti-PCSK9 antibodies.[14-17] Given the intravenous administration 
and high cost of mAbs (>\$14,500 per year), the appeal of small-molecule inhibitors of PCSK9 with lower cost and ease of administration is clear.[18] However, targeting PCSK9 with small-molecule approaches has proven a great challenge due to the lack of druggable pockets on PCSK9. Nevertheless, there has been a rapid increase in reports about small-molecule PCSK9 inhibitors in recent years.[19] Here, we'd like to provide a comprehensive overview of studies on the small molecules targeting PCSK9 in scientific literature and patent applications. We will first give an overview of the biogenesis, structure and physiological role of PCSK9 in lipid metabolism. Then, current strategies reported in the literature based on reducing the synthesis of PCSK9 or disturbing the binding of PCSK9 to the LDLR will be introduced in detail; in addition, several natural products modulating the expression, activity or functionality of PCSK9 will also be described. All international patent applications (2010-2018) protecting novel small molecules targeting PCSK9 will be covered. Finally, novel strategies that have the potential to assist the further development of small-molecule PCSK9 inhibitors and future challenges will be discussed.

\section{Background}

\subsection{Biogenesis and structure of PCSK9}

The human PCSK9 gene, initially called 'neural apoptosis-regulated convertase 1' (NARC1), was discovered by Seidah et al., who reported the identification of the ninth member of the mammalian proprotein convertase family located on chromosome 1p32.3.[20, 21] The PCSK9 gene on the short arm of chromosome 1 is $25 \mathrm{~kb}$ long and contains 12 exons and 11 introns (Figure 1a). PCSK9 encodes an inactive glycoprotein (pre-PCSK9) with 692 amino acids comprising four major components: a signal sequence (1-30) and $N$-terminal prodomain (31-152), followed by a subtilisin-like catalytic domain (153-425) and a $C$-terminal domain (426-692, also called the $\mathrm{V}$ domain).[22] Once the signal peptide is cleaved from pre-PCSK9 in the endoplasmic reticulum, pro-PCSK9 (31-692) is formed and then converted to mature secretory PCSK9 through autocatalytic cleavage of the prodomain between Gln152 and Ser153[23] in the Golgi apparatus (Figure 1b).[24] However, unlike the other 
proprotein convertases, the cleaved prodomain of PCSK9 remains tightly associated with the catalytic domain, where it inhibits further catalytic activity.[25]

PCSK9 binds to LDLRs on the cell surface, leading to their degradation. The binding site of PCSK9 localizes to the EGF(A) (epidermal growth factor A) domain of the LDLR (Figure 1c). The binding surface of PCSK9 is formed primarily by residues 367381 , constructing an exposed, slightly convex $\sim 500 \AA^{2}$ region. The key interactions of PCSK9 with EGF(A) are made by an antiparallel $\beta$-sheet formed between residues 377379 of PCSK9 and 308-310 of EGF(A). In addition, $\operatorname{Arg}^{194}$ and Asp ${ }^{238}$ of PCSK9 are also important for the binding. Other residues of PCSK9 such as $\mathrm{Phe}^{379}, \mathrm{Ile}^{369}$, and Cys $^{378}$ also contribute to this interface (Figure 1d).[26]

a



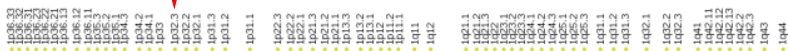
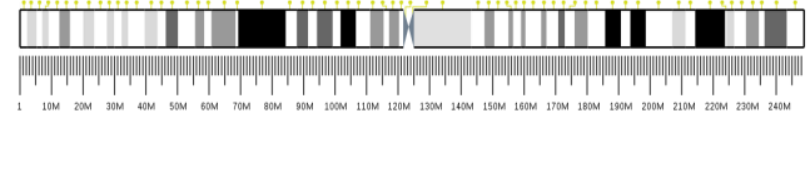

c



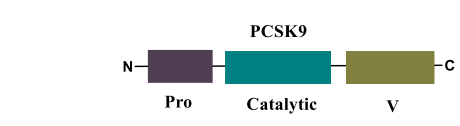

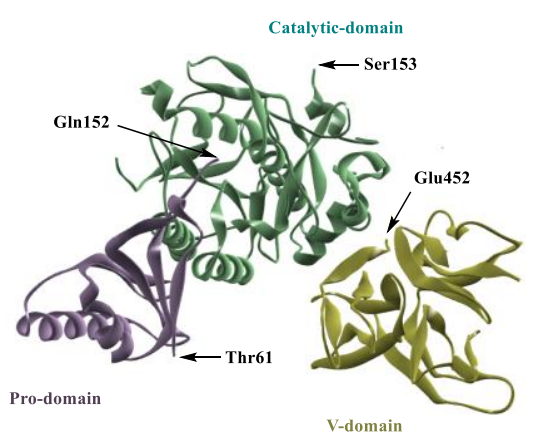

d

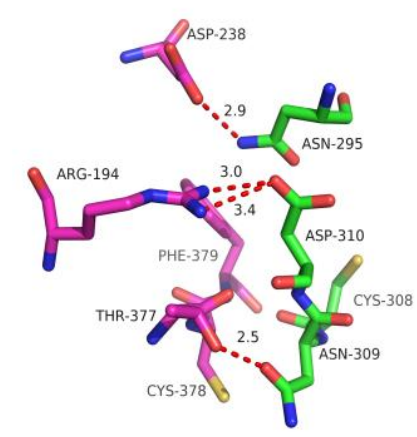

Figure 1. Gene location (human) and structure of PCSK9. (a) Gene location of PCSK9. (b) Structure of PCSK9, with the pro-domain (violet), the catalytic domain (forest), and the V-domain (pale yellow). (c) The binding surface of PCSK9 with EGF-A. The 
surface of PCSK9 buried upon binding to EGF-A is colored according to element type: carbon, warmpink; nitrogen, blue; oxygen, red; sulfur, limon. EGF-A is represented as a marine cartoon model. (d) Key interactions between PCSK9 (magenta) and EGF-A (Green).

\subsection{Physiological role of PCSK9}

In 2003, novel gain-of-function (GOF) mutations (S127R, F216L) in the PCSK9 gene were identified by Abifadel et al. in two French families with autosomal dominant hypercholesterolemia.[27] By contrast, loss-of-function (LOF) mutations have the opposite effect and result in hypocholesterolemia. Since then, PCSK9 has emerged as a novel therapeutic target for the treatment of dyslipidemia. Several lines of evidence have demonstrate an LDL-C lowering mechanism in which PCSK9 lowers the amount of hepatic LDLR proteins and thus compromises the liver's ability to remove LDL-C from circulation.[28] As shown in Figure 2, under normal physiological conditions, circulating LDL is bonded to LDLRs at the hepatocyte surface and then internalized into hepatocytes through clathrin-mediated endocytosis as a receptor-ligand complex. The low $\mathrm{pH}$ in the endosome leads to dissociation of the LDL from its receptor, and the LDL is degraded in the lysosome, while the LDLR is recycled to the cell surface.[29, 30] However, in the presence of PCSK9 at the hepatocyte surface, the catalytic domain of secreted PCSK9 associates with the EGF(A) domain of the LDLR, and the PCSK9/LDLR complex is internalized into hepatocytes.[31] The low $\mathrm{pH}$ of the endosome enhances the affinity of PCSK9 for the LDLR, preventing the receptor from being recycled to the cell surface. Instead, the complex is directed to the lysosome, where LDLR is concomitantly degraded along with the complexed LDL particle.[32, 33]

\subsection{Approaches to PCSK9 inhibition}

After the identification of LOF and GOF mutations of PCSK9 in human, great efforts have been made to discover PCSK9 inhibitors that act as therapeutic agents to lower LDL-C.[34, 35] At least nine different modalities targeting PCSK9 have arisen, 
including mAbs, peptidomimetics, antisense oligonucleotides, small interfering RNA (siRNA), vaccines, CRISPR (clustered regularly interspaced short palindromic repeats) therapeutics, antibody mimetics (including adnectin and anticalin), and small molecules.[36] The potential advantages and disadvantages of these modalities as well as the clinical studies of their effectiveness are summarized in Table 1.

In terms of mechanism, the success of these modalities is roughly attributed in this review to three strategies that target PCSK9 (Figure 2). Strategy 1 is to directly or indirectly prevent binding of PCSK9 to the LDLR on the cell surface with an antibody, a peptide, or a small molecule. Strategy 2 is to interfere with the maturation and secretion processing or the biological function of PCSK9. Strategy 3 is to develop inhibitors of PCSK9 synthesis and expression at the mRNA or protein levels. These three strategies have been successfully applied to develop small-molecule PCSK9 inhibitors in recent years. Although only one PCSK9 small molecule is currently active in clinical trials (see section 3.6.2), there has been a steady increase in available data on small-molecule PCSK9 inhibitors in recent years. This review will provide an updated view of small-molecule PCSK9 inhibitors reported in scientific journals and patent applications. 


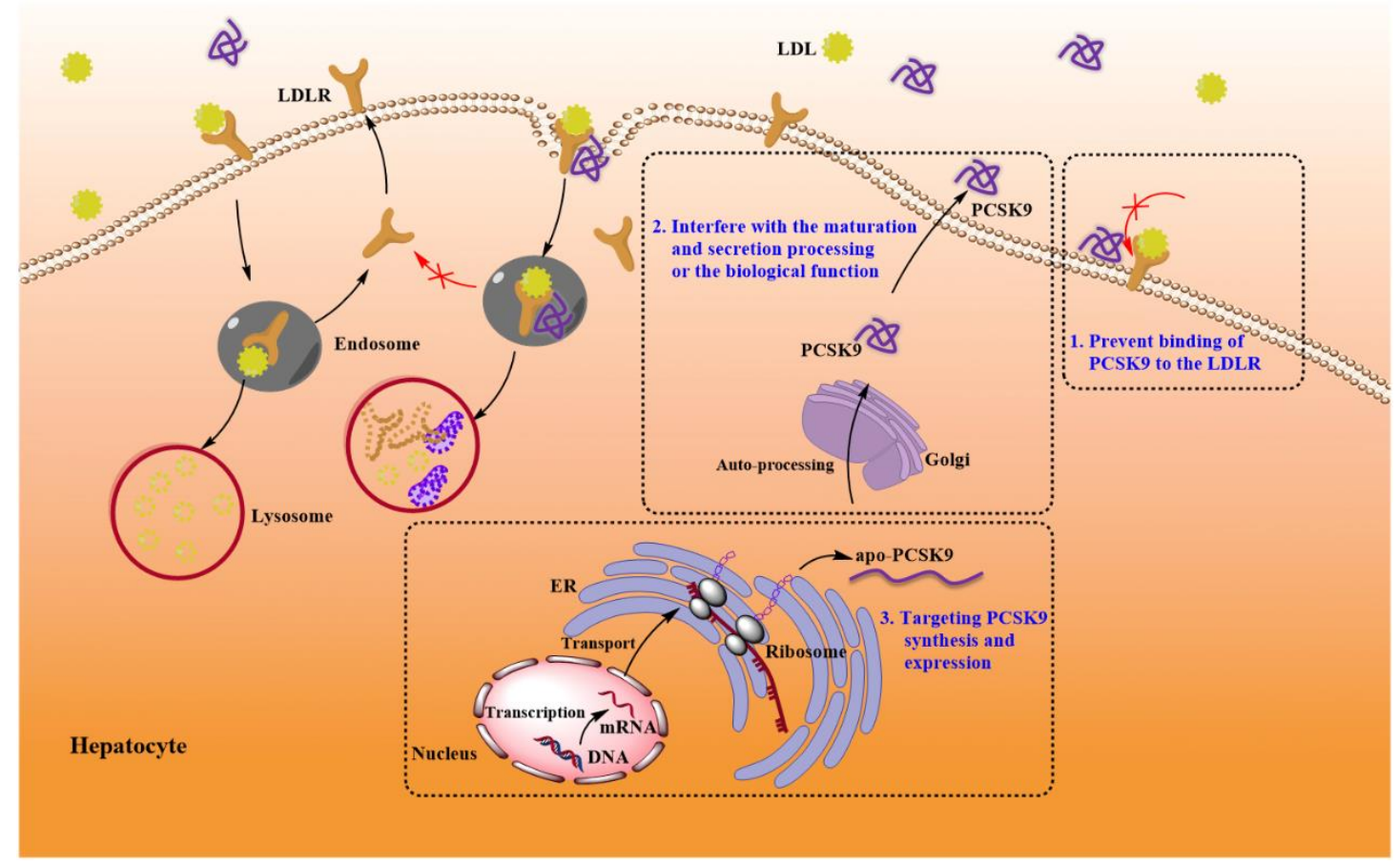

Figure 2. PCSK9 is produced mainly by the liver and is secreted into the bloodstream. Upon binding to liver LDLRs, the entire PCSK9/LDLR complex is endocytosed and subsequently directed to lysosomes for degradation. Strategies targeting the synthesis, processing, and binding of PCSK9 could be adopted to develop PCSK9 inhibitors.

\section{Table 1}

Pharmaceutical approaches targeting PCSK9

\begin{tabular}{|c|c|c|c|c|c|c|}
\hline Approach & Mode of action & Advantages & Disadvantages & Agent[Ref] & Stage & Company \\
\hline $\begin{array}{l}\text { Monoclonal } \\
\text { antibodies } \\
(\mathbf{m A b s})\end{array}$ & $\begin{array}{l}\text { Blocking } \\
\text { interaction with } \\
\text { LDLR or } \\
\text { neutralizing } \\
\text { PCSK9 activity. }\end{array}$ & $\begin{array}{l}\text { Efficient and safe } \\
\text { High specificity } \\
\text { Low toxicity }\end{array}$ & $\begin{array}{l}\text { Short shelf-life } \\
\text { compared with } \\
\text { siRNA } \\
\text { High cost } \\
\text { Parenteral } \\
\text { administration }\end{array}$ & $\begin{array}{l}\text { Evolocumab [10] } \\
\text { Alirocumab [11] } \\
\text { Bococizumab[37] } \\
\text { LY-3015014[38, 39] } \\
\text { RG-7652[40, 41] }\end{array}$ & $\begin{array}{l}\text { Approved-2015 } \\
\text { Approved-2015 } \\
\text { Phrase III } \\
\text { (Discontinued) } \\
\text { Phase II } \\
\text { Phase II }\end{array}$ & $\begin{array}{l}\text { Amgen } \\
\text { Sanofi } \\
\text { Pfizer } \\
\text { Lilly } \\
\text { Genentech/Ro } \\
\text { che }\end{array}$ \\
\hline $\begin{array}{l}\text { Small } \\
\text { Peptides }\end{array}$ & $\begin{array}{l}\text { Blocking } \\
\text { interaction with } \\
\text { LDLR }\end{array}$ & Cheap & $\begin{array}{l}\text { Instability in plasma } \\
\text { Parenteral } \\
\text { administration }\end{array}$ & Pep2 & Pre & Genentech \\
\hline $\begin{array}{l}\text { Antisense } \\
\text { oligonucleo } \\
\text { tides }\end{array}$ & $\begin{array}{l}\text { Silence mRNA } \\
\text { Leading to mRNA } \\
\text { degradation }\end{array}$ & High specificity & $\begin{array}{l}\text { High production } \\
\text { costs } \\
\text { Parenteral } \\
\text { administration }\end{array}$ & $\begin{array}{l}\text { SPC5001[43] } \\
\text { BMS-844421[44] } \\
\text { Civi-007[45] }\end{array}$ & $\begin{array}{l}\text { Phase I } \\
\text { (Discontinued) } \\
\text { Phase I } \\
\text { (Discontinued) } \\
\text { Phase I }\end{array}$ & $\begin{array}{l}\text { Roche } \\
\text { BMS }\end{array}$ \\
\hline
\end{tabular}




\begin{tabular}{|c|c|c|c|c|c|c|}
\hline siRNA & $\begin{array}{l}\text { Target PCSK9 } \\
\text { mRNA and arrest } \\
\text { translation }\end{array}$ & $\begin{array}{l}\text { Long-acting } \\
\text { Safe } \\
\text { Less-frequent } \\
\text { dosing }\end{array}$ & $\begin{array}{l}\text { Parenteral } \\
\text { administration }\end{array}$ & $\begin{array}{l}\text { Inclisiran } \quad(\text { ALN- } \\
60212)[46,47]\end{array}$ & Phase III & $\begin{array}{l}\text { Alnylam/The } \\
\text { Medicines } \\
\text { Company }\end{array}$ \\
\hline Adnectin & $\begin{array}{l}\text { Blocking } \\
\text { interaction with } \\
\text { LDL-R }\end{array}$ & $\begin{array}{l}\text { High binding } \\
\text { affinity } \\
\text { Relative cheaper } \\
\text { production cost }\end{array}$ & $\begin{array}{l}\text { Short plasma half- } \\
\text { life }\end{array}$ & BMS-962476[48] & Phase I & BMS \\
\hline Anticalin & $\begin{array}{l}\text { Blocking } \\
\text { interaction with } \\
\text { LDL-R }\end{array}$ & $\begin{array}{l}\text { Antibody mimetic } \\
\text { but smaller than } \\
\text { mAbs, } \\
\text { Mass production } \\
\text { at low cost }\end{array}$ & $\begin{array}{l}\text { Design and } \\
\text { screening }\end{array}$ & DS-9001a[49] & $\begin{array}{l}\text { Phase I } \\
\text { (Discontinued) }\end{array}$ & $\begin{array}{l}\text { Daiichi } \\
\text { Sankyo/Pieris } \\
\text { Pharmaceutica } \\
\text { ls }\end{array}$ \\
\hline Vaccine & $\begin{array}{l}\text { Immunization } \\
\text { against the body's } \\
\text { own PCSK9 to } \\
\text { produce } \\
\text { autoantibodies }\end{array}$ & $\begin{array}{l}\text { High immune } \\
\text { response against } \\
\text { PCSK9 without } \\
\text { side effects } \\
\text { Long-term effects }\end{array}$ & $\begin{array}{l}\text { Possible } \\
\text { irreversibility } \\
\text { Autoimmune } \\
\text { response }\end{array}$ & AT04A\& AT06A[50] & $\begin{array}{l}\text { Phase I } \\
\text { Phase I }\end{array}$ & $\begin{array}{l}\text { AFFiRis } \\
\text { AFFiRis }\end{array}$ \\
\hline CRISPR & $\begin{array}{l}\text { Genome editing } \\
\text { disrupting } P C S K 9 \\
\text { gene }\end{array}$ & $\begin{array}{l}\text { Permanent } \\
\text { reduction in LDL- } \\
\mathrm{C} \text { levels }\end{array}$ & $\begin{array}{l}\text { Potential off-target } \\
\text { mutagenesis }\end{array}$ & $\begin{array}{l}\text { Academic project and } \\
\text { AstraZeneca[51-55] }\end{array}$ & Preclinical & AstraZeneca \\
\hline $\begin{array}{l}\text { Small } \\
\text { molecules }\end{array}$ & As detailed below & $\begin{array}{l}\text { Cheap } \\
\text { Oral } \\
\text { administration }\end{array}$ & $\begin{array}{l}\text { High likelihood of } \\
\text { off-target }\end{array}$ & As detailed below & Preclinical & $\begin{array}{l}\text { As detailed } \\
\text { below }\end{array}$ \\
\hline
\end{tabular}

\section{Small-molecule PCSK9 inhibitors reported in scientific journals}

\subsection{Blocking the ribosome: from R-IMPP to PF-06815345}

In the search for small molecules that inhibit PCSK9 production, researchers from Pfizer have presented a fascinating work determining PCSK9 secretion through highthroughput screening (HTS).[56] R-IMPP (1, PF-00932239, Figure 3) was identified as a new anti-PCSK9 small lead through a phenotypic screen from a screening set of 2.55 million compounds. This process was challenging based on the following threshold values: for ProLabel tag chemiluminescent assays, $\mathrm{IC}_{50}<10 \mu \mathrm{M}$; for secreted alkaline phosphatase nonspecific secretion assays, $\mathrm{IC}_{50}>10 \mu \mathrm{M}$; and for ATP cytotoxicity assays, $\mathrm{IC}_{50}>10 \mu \mathrm{M}$. Finally, R-IMPP was identified as a weak PCSK9 
antisecretagogue with an $\mathrm{IC}_{50}$ value of $4.8 \mu \mathrm{M}$ in a $\mathrm{CHO}-\mathrm{K} 1$ cell line overexpressing recombinant ProLabel-tagged PCSK9 and an $\mathrm{IC}_{50}$ of $2 \mu \mathrm{M}$ in native cell lines.[57] The pharmacokinetic properties of PF-00932239 were not satisfactory, and structural changes were made to two regions of hit compound (2) to improve its pharmacokinetic properties and potency, resulting compound PF-06446846 (3).[58] PF-06446846 inhibited the secretion of PCSK9 with an $\mathrm{IC}_{50}$ of $0.3 \mu \mathrm{M}$ in Huh7 cells. The mechanism of action of this compound was shown to be new, as it demonstrated the ability to selectively bind to human (but not Escherichia coli) 80S ribosomal complex, causing the ribosome to stall on mRNA near the position predicted to generate a 35 amino acid peptide.[59] This work generated fascinating new insight into the basic biology of ribosomal processing. $[60,61]$

Although PF-06446846 (3) exhibits a high degree of specificity for inhibiting the expression of PCSK9, the narrow margin between PCSK9-lowering and hematopoietic effects prevents the clinical development of PF-06446846. Thus, efforts to achieve better safety by narrowing the tissue distribution of these compounds was continued using a hepatic targeting approach.[62] An acidic/anionic functionality was introduced into benzamide $(\mathbf{4}, \mathbf{5})$ to facilitate liver-targeted delivery of these PCSK9 inhibitors according to previous structure-activity relationships (SARs).[63, 64] Unfortunately, these zwitterions lacked anti-PCSK9 pharmacology in cell-based assays due to their poor permeability. Thus, an exquisite ester, which is labile to carboxylesterase 1 (CES1) in the liver, was added to compounds $\mathbf{4}$ and $\mathbf{5}$ to make prodrugs.[65] Metabolism of these prodrugs in hepatocytes revealed the active zwitterion that was retained by its poor passive permeability. Finally, compound 6 (PF-06815345) was selected as a candidate, as it was relatively well tolerated in 28 day preclinical toxicity studies in rats and monkeys. Further studies are needed to understand the potential of this therapeutic modality and the liver targeting approach.

In parallel, efforts to transform compound $\mathbf{3}$ into molecules with high systemic bioavailability and an improved balance of safety and efficacy suitable for further development were also explored.[66] It was found that subtle structural changes around benzamide and $\mathrm{N}$-triazolopyridine moieties of $\mathbf{3}$ yielded significant changes in 
pharmacology and off-target toxicity. Synthetic SAR evaluations were performed abound these two regions to establish a correlation between substituent and toxicology to seek out the analogues of interest, and resulted in identification of compounds $\mathbf{7}$ and $\mathbf{8}$ with similar potencies and improved in vivo toxicology profiles. The improved safety profile may be related to diminish binding of these compounds to nontranslating ribosomes, but great efforts should be made to understand the translational selectivity.

The strategy adopted by Pfizer was extremely innovative, as translational inhibitors were generally confined to antibacterials;[67] however, Pfizer demonstrated that small molecules can specifically inhibit the translation of a single disease-associated protein by stalling the ribosome chain, truly opening new paradigms to overcoming 'undruggable' proteins. But whether this strategy could be applied to other target to find highly selective translational inhibitors remains unclear. 


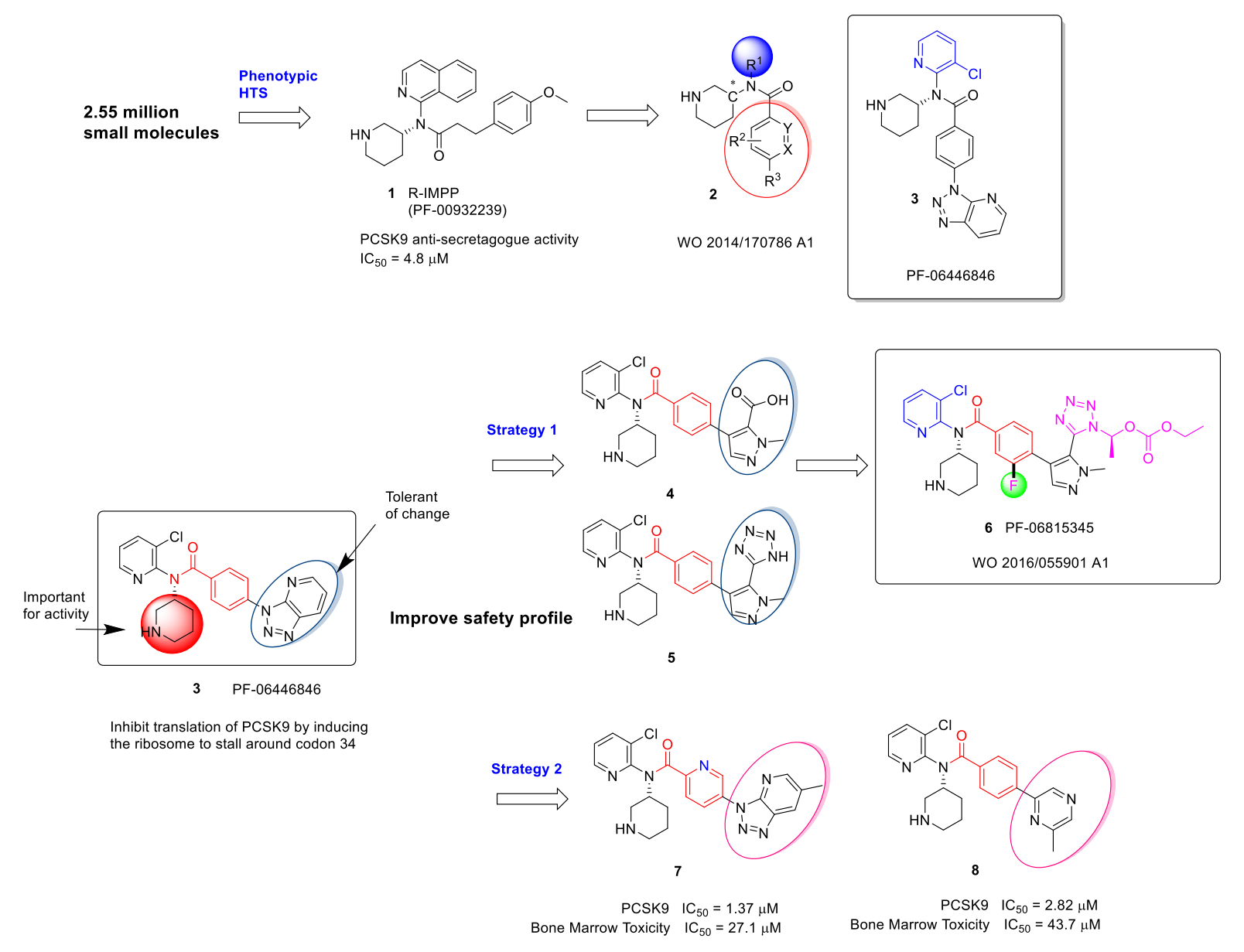

Figure 3. Strategies adopted by Pfizer for the development of PF-06815345 and compounds $\mathbf{7}$ and $\mathbf{8}$.

\subsection{Heparan sulfate mimetics}

It is well known that PCKS9 interacts with the LDLR, causing the receptor to internalize, and consequently reduces the clearance of LDL. However, the PCSK9/LDLR binding constant is in the range of 170-628 nM, while the PCSK9 plasma concentration is approximately $6 \mathrm{nM}$.[68] Thus, as it is unlikely that the PCSK9 in the circulating system binds directly at normal physiological concentrations, some co-receptor may be involved in the interaction between PCSK9 and LDLR. Recently, Gustafsen and colleagues proposed the provocative concept that heparin sulfate proteoglycans (HSPGs) participate as a receptor for PCSK9 in the liver and facilitate the clustering of PCSK9 to LDLR.[69] The authors proved that HSPGs on the hepatocyte surface capture PCSK9 and present it to the LDLR, ensuring the optimal 
conditions for PCSK9/LDLR complex formation. HSPGs participate in the regulation of a wide range of physiological and pathological phenomena, including developmental processes, angiogenesis, blood coagulation, and tumor metastasis.[70] Heparan sulfate (HS) is a linear polysaccharide chain composed of repeating linked pyrosulfuric acid and 2-amino-2-deoxy glucopyranose residues, and two or three HS chains are covalently attached to serine residues of the core proteins to form HSPGs. The HSbinding site on PCSK9 is located in the prodomain of PCSK9 and formed by surfaceexposed basic residues interacting with trisulfated heparan sulfate disaccharide repeats. Heparin or heparan sulfate mimetics, interrupting the HS/PCSK9 interaction directly through binding to the HS-binding surface on PCSK9, would reduce PCSK9 activity and to be developed as PCSK9 inhibitors.[69]

Several molecules mimicking the structure of heparin, including dextran sulfate (9), pentosan sulfate (10), suramin (11) and the phosphorothioate oligonucleotide S-dC-36 (12), were screened for their abilities to inhibit PCSK9 and increase LDLR in HepG2 cells. S-dC-36 (12) was the most potent HS mimetic binding PCSK9 with a $K_{\mathrm{D}}$ of 4.8 $\mu \mathrm{M}$. Interestingly, five clinical trials for anticoagulation with low-dose heparin at subtherapeutic amounts all reported marked reductions in cardiac events, although the mechanism for this has remained unclear.[71-75] The results from Gustafsen and colleagues may partly explain this phenomenon. In addition, chitosan oligosaccharides, linear polymers of $\mathrm{N}$-acetyl-D-glucosamine and deacetylated glucosamine, were recently reported to enhance the level of lipid droplets via downregulation of PCSK9 gene expression, suggesting saccharide might be a potential source of PCSK9 inhibitors.[76] It should be noted that the binding affinities of these heparan sulfate mimetics to PCSK9 were not high, further structural modifications with these molecules as leading compounds to find potent small-molecule PCSK9 inhibitors might be an effective method. 


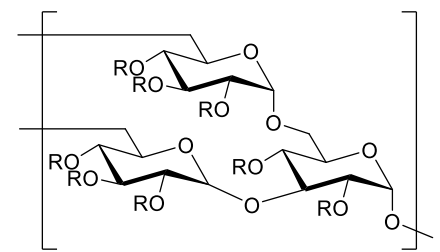

9 Dextran sulfate $K_{\mathrm{d}}=180 \mu \mathrm{M}$

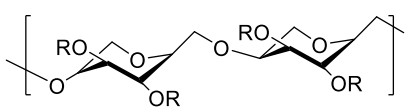

10 Pentosan sulfate $\mathrm{R}=\mathrm{SO}_{3}^{-}$or $\mathrm{H}$ $K_{\mathrm{d}}=381 \mu \mathrm{M}$

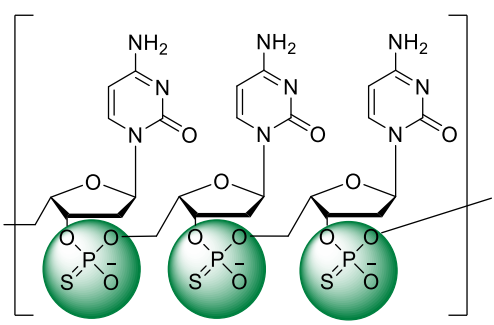

$12 \mathrm{~S}-\mathrm{dC}-36$

Suramin
$K_{\mathrm{d}}=190 \mu \mathrm{M}$

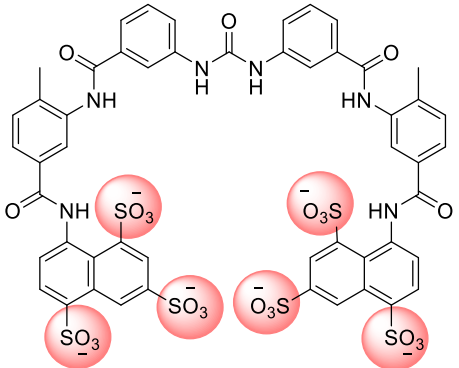

Figure 4. Heparan sulfate mimetics as PCSK9 inhibitors.

\section{3. $C B \_36$ from in silico screening}

Although the motif of PCSK9 that binds to the EGF(A) domain of LDLR has been well characterized, the application of this interaction for the in silico virtual design of small molecules is a great challenge due to the lack of appropriate binding pocket. Min and co-workers tried to develop small-molecule inhibitors using a in silico virtual screening approach based on the PCSK9/LDLR interaction.[77] PCSK9 amino acids from 367 to 381, located where the EGF(A) domain of the LDLR binds, were extracted and assigned to be the target of the inhibitors. The PCSK9 protein structure from Protein Data Bank (PDB) was pretreated by removing the $\mathrm{EGF}(\mathrm{A})$ domain and water molecules, followed by the supplementation of hydrogen atoms. Subsequently, GOLD software version 4.0.1 was used to calculate the docking scores of $\sim 450,000$ chemicals from the ChemBridge Express database. The top 100 chemicals with the highest docking scores were selected to evaluate their in vitro activities using a PCSK9/LDLR binding assay, immunoblot analysis, and an LDL-C uptake assay. Most of the potent compounds (13) have fragments that structurally resemble the plasticizer bisphenol $\mathrm{A}$ and were protected in WO 2016/108572 A2.[78] The most potent chemical, CB_36 (14), was 
validated as an inhibitor perturbing the linkage between PCSK9 and LDLR in a dosedependent manner. However, whether this compound directly binds to PCSK9 and exerts its effects mediated by PCSK9 in a specific-manner remains to be proven.



13 WO 2016/108572 A2

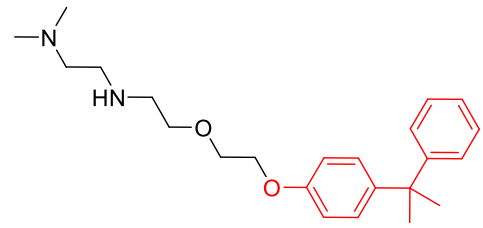

14 CB_36

Figure 5. CB_36 from in silico screening.

\subsection{Imidazole-based minimalist peptidomimetic}

Disrupting the protein-protein interaction (PPI) between PCSK9 and LDLR is an effective strategy, and several peptides have been developed accordingly.[42, 79] However, the search for alternatives to peptides, such as secondary-structure mimics of the main recognition motifs, that can be induced to fold into protein-like bioactive conformations that include a-helices, $\beta$-turns and $\beta$-strands, has received less attention.[80] The X-ray crystal structure of PCSK9/LDLR clearly showed a $\beta$-strandmediated interaction formed by the residues C378-F379-V380-S381 of PCSK9 and V328-C329-N330-D331 of LDLR.[81] This evidence suggests that a small $\beta$-strand peptidomimetic resembling these native $\beta$-strand sequences (15), can function as a PCSK9 inhibitor through interfering with the PCSK9/LDLR reciprocal interaction.

Stucchi and co-workers reported a multicomponent synthesis of a novel imidazolebased peptidomimetic (17), that mimicked the conformation of a $\beta$-strand in terms of both the side chain orientation and the interstrand H-bond donating capability (Figure 6).[82] This peptidomimetic is more like a small molecule than a peptide as its molecule weight is $395 \mathrm{Da}$. Remarkably, the in vitro PCSK9-LDLR binding assay showed that this compound induces a concentration-dependent inhibition of the PPI and that the $\mathrm{IC}_{50}$ value is $11.2 \pm 0.2 \mu \mathrm{M}$. Reducing the number of imidazole rings from 4 to 3 caused a significant decrease in the $\mathrm{IC}_{50}$, suggesting the importance of the tetraimidazole scaffold. However, a fluorescent-LDL uptake experiment showed that this compound 
increased the LDL uptake with an $\mathrm{EC}_{50}$ of $6.04 \mu \mathrm{M}$, which was lower than the $\mathrm{IC}_{50}$ for the binding affinity of this compound to PCSK9.

Although $\beta$-strand peptidomimetics have been successfully applied as enzyme inhibitors,[83] this report is the first of an imidazole-based minimalist $\beta$-strand mimic as a PCSK9 inhibitor. This $\beta$-strand mimic paves the way for the future development of a new class of PCSK9 inhibitors. Future development of peptidomimetics might be focused on the number of imidazoles and the substitutions of imidazoles and $N-\mathrm{Me}$ groups to mimic the LDLR $\beta$-strand more strictly to improve the specificity.

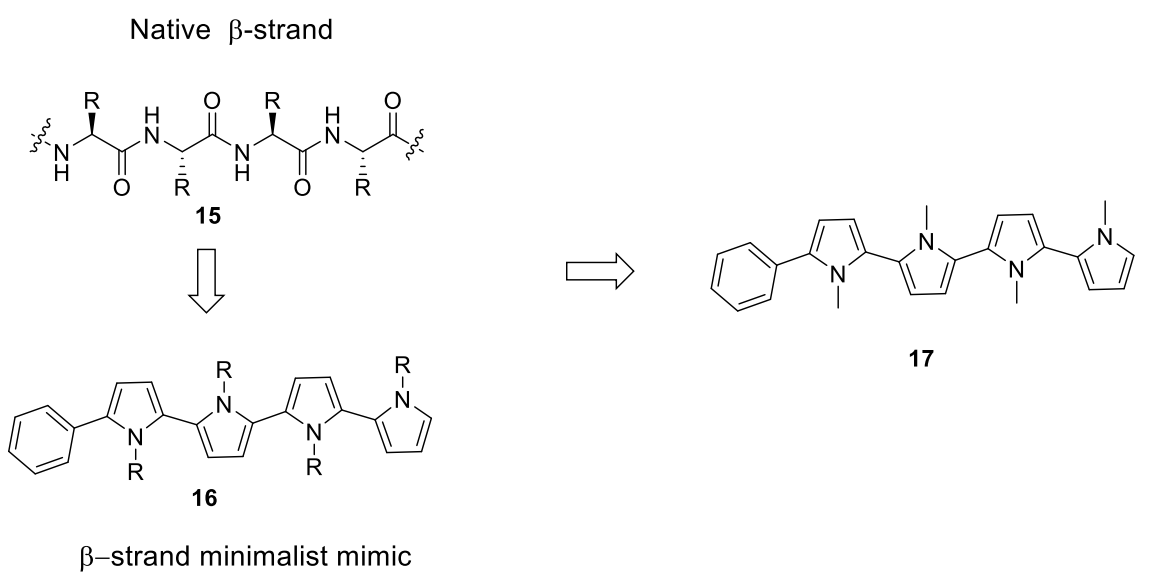

Figure 6. Small $\beta$-strand peptidomimetics as PCSK9 inhibitors.

\subsection{Discovery of semirigid scaffold using Exploring Key Orientations}

A recent story about peptidomimetics comes from Burgess and co-workers.[84] They hypothesized that a set of privileged conformational mimics of semirigid scaffolds bearing amino acid side-chains could be compared with PPI-interface regions to facilitate the development of peptidomimetics to perturb the PPI. They call this concept Exploring Key Orientations (EKOs), and developed a data mining algorithm to find such chemotypes that match PPI interfaces and, thereby perturb the interface. $[85,86]$ In 2018, several candidate chemotypes were conceived and screened as PCSK9 inhibitors using the EKO approach by the Burgess group. They found that molecule 18 was superimposed on LDLR in the PCSK9/LDLR complex in several ways. Specifically, five groups of interface side-chains of LDLR in the PCSK9/LDLR crystal 
structure $\left(\mathrm{Asp}^{299}, \mathrm{Leu}^{298}\right.$, and $\mathrm{Asp}^{301} ; \mathrm{Cys}^{297}, \mathrm{Asn}^{301}$, and $\mathrm{Asp}^{299} ; \mathrm{Leu}^{298}, \mathrm{Asp}^{299}$, and $\mathrm{Asn}^{301} ; \mathrm{Val}^{307}, \mathrm{Cys}^{308}$, and $\mathrm{Leu}^{318} ; \mathrm{Asn}^{309}, \mathrm{Cys}^{308}$, and $\mathrm{Leu}^{318}$ ), might be overlaid by compound 18. Interestingly, Asp ${ }^{299}$, $\mathrm{Leu}^{318}$, and $\mathrm{Asn}^{309}$ were implied as "hot spots" in LDLR side-chains implicated in the PCSK9/LDLR interface based on crystallographic studies.[28] Subsequently, the $\mathrm{R}^{1}-\mathrm{R}^{3}$ side chains in compound $\mathbf{1 8}$ were replaced with the natural side chains from the LDLR protein, and a series of compounds were prepared and tested using a time-resolved fluorescence resonant energy transfer (TRFRET) assay. However, inconclusive results compelled the authors to improve the affinity of these compounds by appending additional pharmacophores using an iterative docking and energy minimization procedure. Consequently, structures 19 were conceived by including an Arg at the $C$-terminus of structure of $\mathbf{1 8}$ to fill the negative pocket in PCSK9. A solid-phase synthesis method was applied to install the $\mathrm{R}^{1}-\mathrm{R}^{4}$ side chains of chemotype 19, and 15 compounds were finally prepared for screening. Three hit compounds exhibited promising dissociation constants for PCSK9 binding in surface plasmon resonance (SPR) analyses: 20 (LDLL-1dlnr, $K_{\mathrm{d}} 24.8 \pm 9.1 \mu \mathrm{M}$ ), 21 (DLLD-1nclk, $K_{\mathrm{d}} 41.2 \pm 17.5 \mu \mathrm{M}$ ), and 22 (LDLL-1dl(CN)r, $\left.K_{\mathrm{d}} 35.8 \pm 11.4 \mu \mathrm{M}\right)$. In addition, LDLL-1dlnr (20) was modified with a photoaffinity label and found to form a covalent conjugate with PCSK9 upon photolysis. It should be noted, as complex unnatural amino acids, further modifications on these amino acid side-chains to regulate the lipid-water partition coefficient and improve bioavailability are need. 

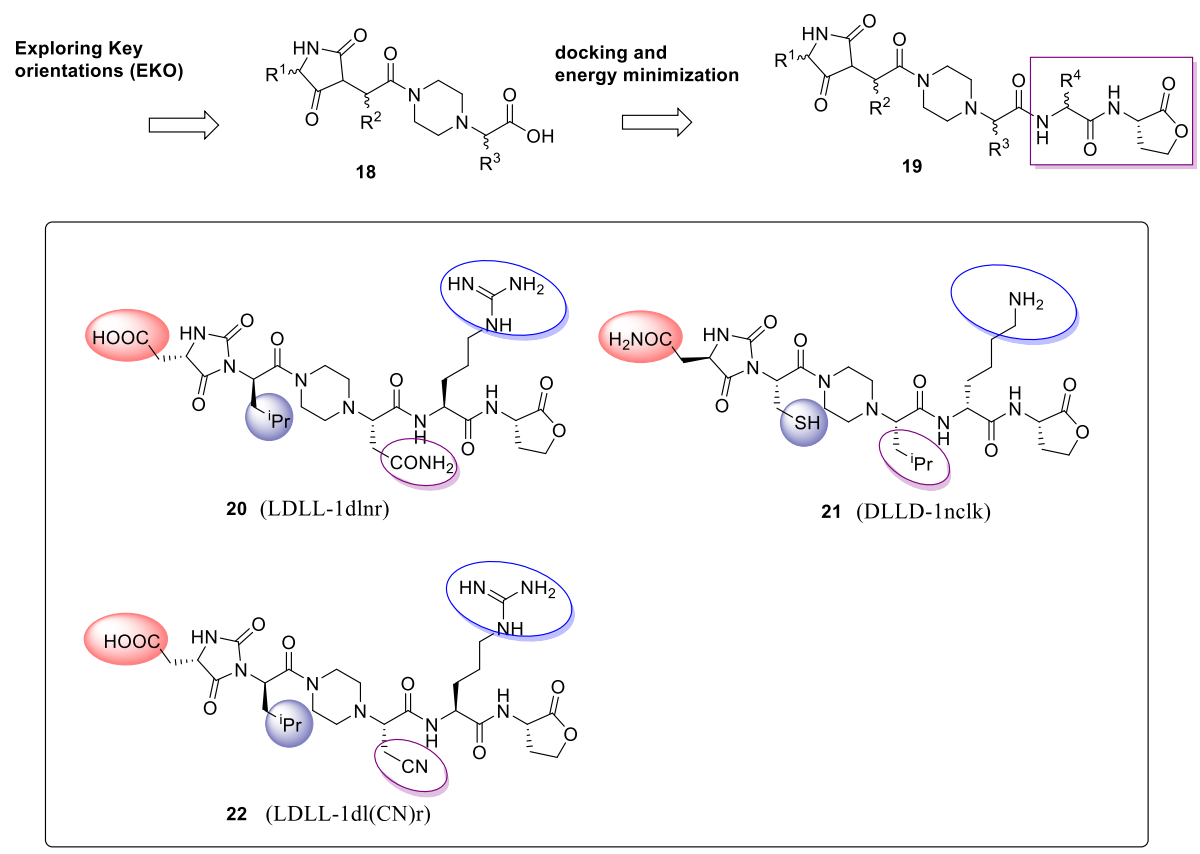

Figure 7. Discovery of semirigid scaffold using Exploring Key Orientations strategy.

\subsection{Natural products}

Despite of the high efficacy of approved PCSK9 antibody drugs, a few studies of developing natural products as lipid-lowering agents have been reported in recent years. $[87,88]$ Some of these natural products have been reported to hinder the function of PCSK9 directly or indirectly.[89, 90] Berberine, corydaline, curcumin, lignans, polydatin, flavones, etc. have been widely studied and identified to lower the expression of PCSK9. The mechanism studies of these natural products showed that most of these compounds alter PCSK9 status through modulating either PCSK9 expression or mature protein secretion. However, more mechanistic investigations of these natural products are required, and these studies would facilitate reveling the signaling pathways associated with PCSK9. In the following section, we will review natural products with potential PCSK9 inhibitory effects.

\subsubsection{Berberine}

Berberine (23, BBR, Figure 8) is an isoquinoline plant alkaloid isolated from Berberis, such as Rhizoma coptidis, Scutellaria baicalensis and Phellodendron amurense.[91] In recent years, increasing evidence has suggested an ability of BBR to improve lipid 
metabolism, and several clinical studies have also tested the efficacy of BBR in humans $[92,93]$ and implied that BBR administration might be a potential therapeutic approach for hypercholesterolemia. Studies have shown that BBR significantly increased LDLR expression through a posttranscriptional mechanism that stabilizes the LDLR mRNA[94] and that it reduced the expression and secretion of PCSK9.[95] However, the detailed mechanism by which BBR affects PCSK9 expression remains unclear. Cameron and co-workers suggested that BBR decreased PCSK9 mRNA and protein levels in a time- and dose-dependent manner and that this effect was not due to increased degradation of PCSK9 mRNA but most likely to decreased transcription of PCSK9.[95] Subsequently, sterol regulatory element binding protein-2 (SREBP-2) and hepatocyte nuclear factor $1 \alpha(\mathrm{HNF}-1 \alpha)$ were identified to have roles in the BBRmediated suppression of PCSK9 transcription.[96] A highly conserved HNF-1 binding site located between the SRE and Sp1 sites was identified as a critical cis-regulatory sequence of the PCSK9 promoter.[96] 


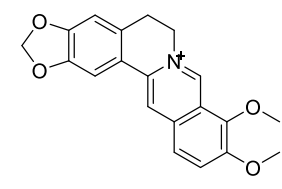

23 Berberine



27 Schinlignan D

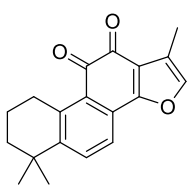

31 Tanshinone IIA

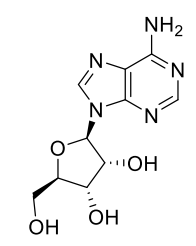

35 Adenosine<smiles>COc1cc(O)c2c(c1)OC(c1ccccc1)CC2=O</smiles>

39 Pinostrobin

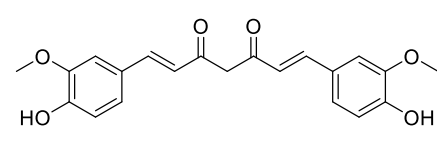

24 Curcumin

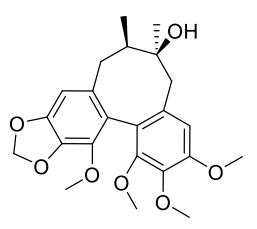

28 Schisandrol B

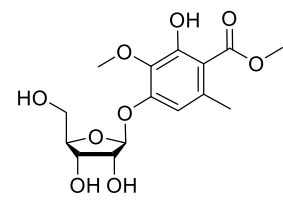

32 Sparoside A



36 Skullcapflavone II

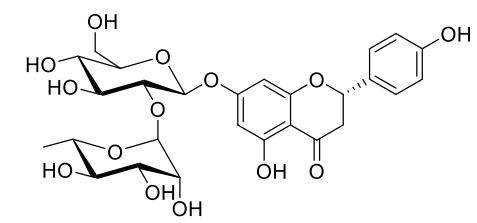

40 Naringin

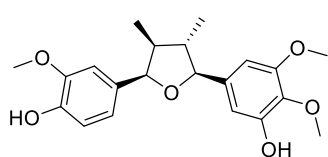

25 Manglisin E

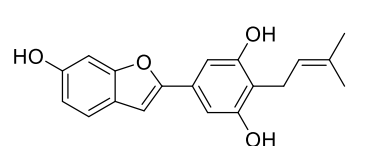

29 Moracin C<smiles>COc1cc2c(c(O)c1O)COC2=O</smiles>

33 Hanabiratakelide A



37 (2R,3R)-3,7,2'-trihydroxy -5-methoxy-flavanone

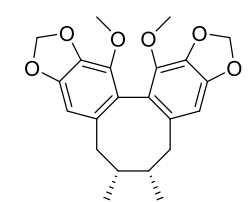

26 Schisandrin C



30 Polydatin



34 5a,6a-epoxy-

(22E,24R)-ergosta-
8(14),22-diene-3 $\beta, 7 \beta-$

diol

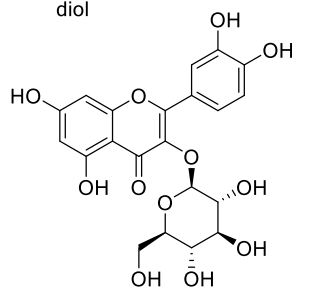

38 Quercetin-3-glucoside

Figure 8. Structures of some natural products with potential PCSK9 inhibitory effects.

\subsubsection{CVI-LM001 from corydaline}

Corydaline (41, Figure 9) is an isoquinoline alkaloid with antiacetylcholinesterase, antiallergic and antinociceptive activities isolated from traditional Chinese herb Corydalis yanhusuo.[97, 98] Recent studies showed that corydaline also possesses several other pharmacological activities, including antienterovirus, [99] antiplatele,[100] and antifungal activities.[101] The lipid-lowering effect of corydaline or its derivatives have rarely been reported. Nevertheless, in 2008, CVI Pharmaceuticals (CVI) disclosed the hypocholesterolemic effects of compounds or derivatives from Corydalis. In their 
disclosed patent, a series of isoquinolinyl-containing alkaloids, such as corydaline, corlumidin, corypalmine, bicuculline, tetrahydropalmatine, egenine and their derivatives were protected as hypocholesterolemic agents.[102, 103] The compounds disclosed there also lower total cholesterol (TC), LDL-C, and triglycerides. CVILM001 (42), the fluorobenzenesulfonate derivative of corydaline, was selected for preclinical studies, and the results confirmed the hypolipidemic effect of CVI-LM001 in hypercholesterolemic animal models, including a hamster model of hyperlipidemia and a diet-induced hyperlipidemia model in rabbits. The mechanism studies demonstrated that increases in hepatic LDLR expression, inhibition of PCSK9 expression and activation of AMP-activated protein kinase (AMPK) might explain the lipid-lowering efficacy of CVI-LM001. In February 2016, CVI initiated two small phase I clinical trials in China to estimate the preliminary pharmacokinetic and safety profiles of CVI-LM001.[104] It should be noted that although CVI-LM001 is a derivative of a natural product, it is the world's first orally administered small-molecule PCSK9 inhibitor in clinical studies. Recently, Liu and other inventors from the Shanghai Institute of Materia Medica described that phenyl [a]indole[2,3-g]quinolizine compounds can be used for treating diseases related to PCSK9 (WO 2017/167202 A1)[105]. The disclosed compounds possess a quinolizine skeleton, which is similar to natural product corydaline (41), typical compound C97 (43) is described in Figure 9.
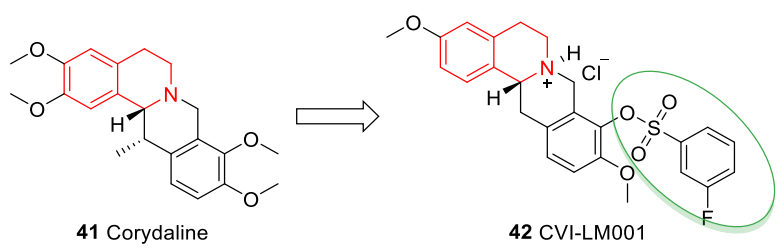
WO 2011/006000 A1
WO 2010/075469 A1

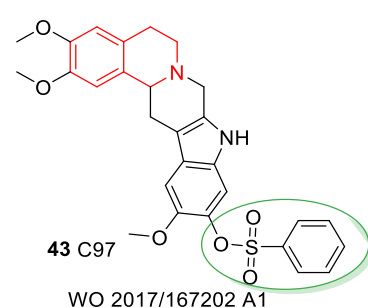

WO 2017/167202 A1

Figure 9. Development of CVI-LM001 from corydaline and related analogues reported in patent WO 2017/167202 A1.

\subsubsection{Curcumin}

Curcumin (24, Figure 8) is a polyphenolic diarylheptanoid found in turmeric, a spice derived from the rhizomes of the plant Curcuma longa Linn.[106] Mounting evidence 
has demonstrated its positive effects in the treatment and prevention of cancer, Alzheimer's disease, multiple sclerosis, etc.[107] The lipid-lowering effect of curcumin has been witnessed in several experimental and clinical studies.[108, 109] In 2014, Tai and co-workers showed that curcumin increased LDLR expression through the suppression of PCSK9 expression and that HNF-1 $\alpha$ is the curcumin-responsive element of the PCSK9 regulator.[110] Recently, the inhibitory effect of curcumin on PCSK9 in rat liver cirrhosis was also evaluated, and the results showed that curcumin protected against intestinal origin endotoxemia by inhibiting PCSK9 to promote LDLR expression.[110] However, the global pharmacological effects of curcumin may impend the further development of curcumin as PCSK9 expression inhibitor due to its multiple molecular targets. It should be noted that curcumin shows positive results in most drug screening assays and is regarded as a pan-assay interference compound, which may lead to misinterpretations of results. Some researchers even conclude that "curcumin is an unstable, reactive, nonbioavailable compound and, therefore, a highly improbable lead".[111]

\subsubsection{Lignans}

The lignans are a large group of polyphenols found in many vascular plants and have relevant health properties, including anticarcinogenic, anti-inflammatory and antioxidant activity.[112] Recently, a bioactivity-guided isolation of the fruits of $S$. chinensis using a PCSK9 mRNA expression screening assay identified the hexanesoluble extract as the active part. It total, 30 compounds were characterized, and four compounds potently inhibited PCSK9 mRNA expression: a tetrahydrofuran-type lignan (manglisin E (25), with an $\mathrm{IC}_{50}$ value of $3.15 \mu \mathrm{M}$ ), and three dibenzocyclooctadienetype lignans (schisandrin C (26), schinlignan D (27), and schisandrol B (28), with $\mathrm{IC}_{50}$ values of 3.85, 0.36, and $1.10 \mu \mathrm{M}$, respectively) (Figure 8).[113]

\subsubsection{Moracin $C$}

Several nutritional compounds (NUTs) have been used against hypercholesterolemina as an alternative to pharmacological therapy. One innovative NUT combination 
$\left(\right.$ LopiGLIK $\left.^{\circledR}\right)$, containing red yeast rice (monacolin K $3.3 \mathrm{mg}$ ), berberine $(531.25 \mathrm{mg}$ ) and leaf extract of Morus alba (200 mg), has exhibited beneficial effects in reducing the plasma levels of the TC and LDL-C by $9.8 \%$ and $12.6 \%$, respectively.[114] The hypolipidemic activity and mechanism of berberine have been studied extensively; however, the chemical constituents and mechanism responsible for the hypolipidemic activity of Morus alba extracts still need deep research.[115] Recently, a study from Pel and co-workers showed that moracin C (29) inhibited PCSK9 mRNA expression and thereby decreased the degradation of LDLR, which could be the active component responsible for the hypolipidemic effect of Morus alba extracts.[116] A PCSK9 mRNA expression monitoring assay in HepG2 cells first isolated and identified 15 compounds from a chloroform-soluble extract of dried Morus alba fruits, and subsequent assays showed that moracin C inhibited PCSK9 mRNA expression with an $\mathrm{IC}_{50}$ value of 16.8 $\mu \mathrm{M}$ in HepG2 cells.

\subsubsection{Polydatin}

Resveratrol is a biologically active stilbenoid present in various plant species and known to have numerous health-promoting effects. Since polydatin (30) is a glycoside precursor of resveratrol (resveratrol-3-O- $\beta$-mono-D-glucoside), its regulation on lipid metabolism has attracted considerable attention.[117] To explore the possible mechanism by which polydatin acts on lipid metabolism, Wang et al. evaluated the role of polydatin in insulin-resistant HepG2 cells and $d b / d b$ mice. The results showed that polydatin not only upregulated the protein level of LDLR but also inhibited both the expression of PCSK9 and its interaction with LDLR in insulin-resistant HepG2 cells. In addition, polydatin significantly enhanced glucokinase and LDLR protein levels and inhibited PCSK9 expression in the liver.[118]

\subsubsection{Tanshinone IIA}

Tanshinone IIA (31) is a phenanthrene-quinone constituent of the Chinese medicinal herb Danshen (Salvia miltiorrhiza), which has been used clinically in Asia for the prevention and treatment of CVD.[119] A hypocholesterolemic effect of tanshinone 
IIA was reported recently by Chen and co-workers.[120] They demonstrated that tanshinone IIA significantly increased the amount of LDLR and LDL uptake activity in HepG2 cells via posttranscriptional regulation. The expression of PCSK9 mRNA and mature protein was also inhibited by tanshinone IIA in HepG2 cells. Further mechanism studies showed that tanshinone IIA increased the nuclear forkhead box O3a (FoxO3a) level, enhanced FoxO3a/PCSK9 promoter complex formation and decreased the PCSK9 promoter-binding ability of HNF-1 $\alpha$, resulting in the suppression of PCSK9 gene expression. These results demonstrate that tanshinone IIA modulates cholesterol via downregulation of PCSK9 expression in hepatic cells. However, Jia et al. showed the conflicting result that tanshinone IIA promoted PCSK expression in the livers of hyperlipidemic rats, by upregulating the mRNA expression levels of SREBP-2 and PCSK9.[121] Further studies might be required to investigate the underlying molecular mechanisms of tanshinone IIA and make a definitive conclusion.

\subsubsection{Aromatic compounds from Sparassis crispa}

Sparassis crispa (Wulf.) is a species of fungus in the genus Sparassis. It is a medicinal mushroom whose fruiting bodies possess various bioactive substances such as $\beta$-glucan, benzoate derivatives, maleic acids, and sesquiterpenoids.[122] Recently, fourteen compounds were isolated by Bang and co-workers from the EtOAc-soluble extracts of the fruiting bodies of S. crispa.[123] Among them, four compounds exhibited potent inhibition of PCSK9 mRNA expression: sparoside A $\left(32, \quad \mathrm{IC}_{50}=20.07 \mu \mathrm{M}\right)$, hanabiratakelide A $\left(33, \mathrm{IC}_{50}=7.18 \mu \mathrm{M}\right), 5 \alpha, 6 \alpha$-epoxy-(22E,24R)-ergosta-8(14),22diene- $3 \beta, 7 \beta$-diol $\left(34, \mathrm{IC}_{50}=8.23 \mu \mathrm{M}\right)$, and adenosine $\left(35, \mathrm{IC}_{50}=18.46 \mu \mathrm{M}\right)$.

\subsubsection{Flavonoids and flavanones}

Flavonoids and flavanones have been reported to down-regulated the PCSK9 gene expression. A methanolic extract of S. baicalensis was recently found to inhibit PCSK9 mRNA expression by Chin and co-workers. Nine compounds were isolated and compounds 36 (skullcapflavone II) and 37 (3,7,2'-trihydroxy-5-methoxy-flavanone) exhibited inhibitory activity at $20 \mu \mathrm{M}(42.4 \%$ and $84.4 \%$, respectively). Further studies 
showed that the expression of SREBP-1 mRNA was downregulated by compounds 36 and 37, indicating that inhibition of PCSK9 mRNA was mediated by SREBP-1.[124] Quercetin is one of the most abundant dietary flavonoids with an average daily consumption of 25-50 mgs.[125] Quercetin is the aglycone form of many flavonoid glycosides, such as quercitrin, guaijaverin, hyperoside, and isoquercitin, and quercetin3-glucoside $(\mathrm{Q} 3 \mathrm{G}, 38)$ is the quercetin 3-O- $\beta$-D-glucoside. This flavonoid glycoside has been shown to reduce diet-induced hyperlipidemia and atherosclerosis in mice.[126] Mbikay et al. examined the effects of micromolar concentrations of Q3G on LDLR and PCSK9 expression using human Huh7 hepatocytes, and the results showed that Q3G decreased the mRNA expression of PCSK9 by 20-30\% while increasing the mRNA and protein expression of LDLR by 60 and 300-400\%, respectively. Treatment with Q3G significantly reduced PCSK9 secretion, thereby causing its intracellular accumulation, and this PCSK9 retention might be partly due to induced sortilin deficiency.[127] Pinostrobin (39) was also found to inhibit the PCSK9 promoter activity and the suppression of PCSK9 mRNA expression in HepG2 cells through the up-regulation of the FoxO3a level.[128] Very recently, naringin (40), a flavanone-7-Oglycoside, was shown to activate AMPK, resulting in down-regulated expression of PCSK9 in obese C57BL/6J mice.[129]

\subsubsection{Other extracts from natural products}

Apart from the abovementioned compounds, some crude extracts from natural products also demonstrated lipid-lowering effects by regulating PCSK9 directly or indirectly. An aqueous extract Phaleria macrocarpa (Scheff.) Boerl fruit was reported by Chong et al. to reduce cholesterol levels in vitro and in vivo.[130] Further mechanism studies showed that $P$. macrocarpa extract significantly upregulated both LDLR and PCSK9 at the protein and mRNA levels, suggesting a mechanism that is similar to statininduced effects. Xuezhikang $(\mathrm{XZK})$ is an extract from red yeast rice that contains a mixture of lovastatin, plant sterols, isoflavones, and other components. XZK is believed in China to be a useful nutraceutical for patients with cardiovascular disorders.[131] Recent studies demonstrated that XZK increased PCSK9 levels through the SREBP-2 
pathway,[132] which was similar to the mechanism behind the lipid-lowering effects of simvastatin.[133] In addition, some studies demonstrated that dietary n-3 polyunsaturated fatty acids reduced plasma PCSK9 concentration and hepatic PCSK9 mRNA expression, thereby exerting lipid-lowering effects.[134]

\section{Small-molecule PCSK9 inhibitors reported in patents}

The interface between PCSK9 and LDLR is extended, flat, and without deep binding pockets, which makes the interface a difficult target for small molecules. There is limited scientific literature reporting small molecules that directly inhibit the interaction between PCSK9 and LDLR; however, a few companies and institutions developed a series of small molecules targeting PCSK9/LDLR PPI, and some even disclosed the technical details.[135] In general, the strategies adopted by these companies targeting PCSK9/LDLR PPI are (a) altering the conformation of the protein PCSK9 through an allosteric mechanism and (b) targeting the "hot spots" of binding sites between PCSK9 and LDLR. In addition, a considerable portion of the pharmaceutical company's strategies focused on developing small molecules that inhibit PCSK9 expression at the genetic or protein levels. However, these small-molecule PCSK9 expression modulators might target other signal pathways and modulate PCSK9 expression indirectly, causing potential off-target effects. In addition, there are several patents that did not disclose the mechanism of their molecules. In this section, we will review the international patent publications reporting novel small molecules targeting PCSK9 for the treatment of CVDs. A brief summary of these patents is given in Table 2 .

\subsection{Small molecules targeting the PCSK9/LDLR PPI}

Three patents, all from Portola Pharmaceuticals, disclosed that tetrahydroisoquinolines (44-46, WO 2017/034990 A1),[136] phenylalanines (47-49, WO 2017/034994 A1),[137] and phenylpiperazines (50-52, WO 2017/034997 A1) [138] increased LDLuptake into liver cells, and LDLR cell surface populations (Figure 10). They declared that these compounds worked as ligands that directly bind the PCSK9 protein and differentially modify PCSK9 biological activity, changing the interactions between 
PCSK9 and LDLR. However, researchers of Portola have not reported any direct evidence in these patents that these small organic molecules bind PCSK9.
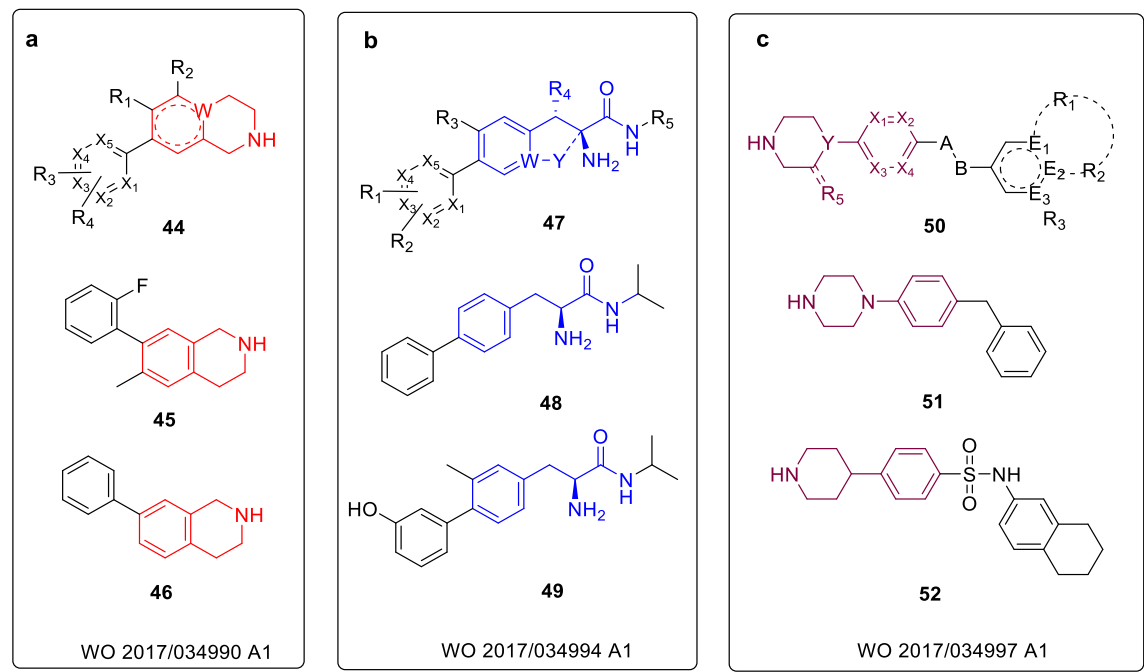

Figure 10. Markush structures and representative compounds from Portola. (a): tetrahydroisoquinolines; (b) phenylalanines; (c) phenylpiperazine.

Workers from the Shifa Biomedical Corporation have disclosed a series of compounds that modulate the physiological action of PCSK9, including its interaction with the LDLR. Various in vitro and in vivo assays have supported the biological activities of compounds claimed in three patents (WO 2014/150326 A1, WO 2014/150395 A1, and WO 2017/222953 A1).[139-141] Some compounds inhibited the PCSK9/LDLR interaction, and the detailed data were disclosed in WO2017222953. The most potent benzofuran compound against the PCSK9/LDLR interaction was SBC115,337 (56), with an $\mathrm{IC}_{50}$ value of $0.5 \mu \mathrm{M}$ (Figure 11). SBC-115,337 (56), SBC110,686 (57), SBC-110,733 (58), SBC-110,736 (59), SBC-110,034 (60), and SBC115,076 (61) were tested for their efficacy in male mice (C57BL/6 mice), and the data demonstrated that these compounds significantly lowered cholesterol levels (20\%$38 \%)$. 

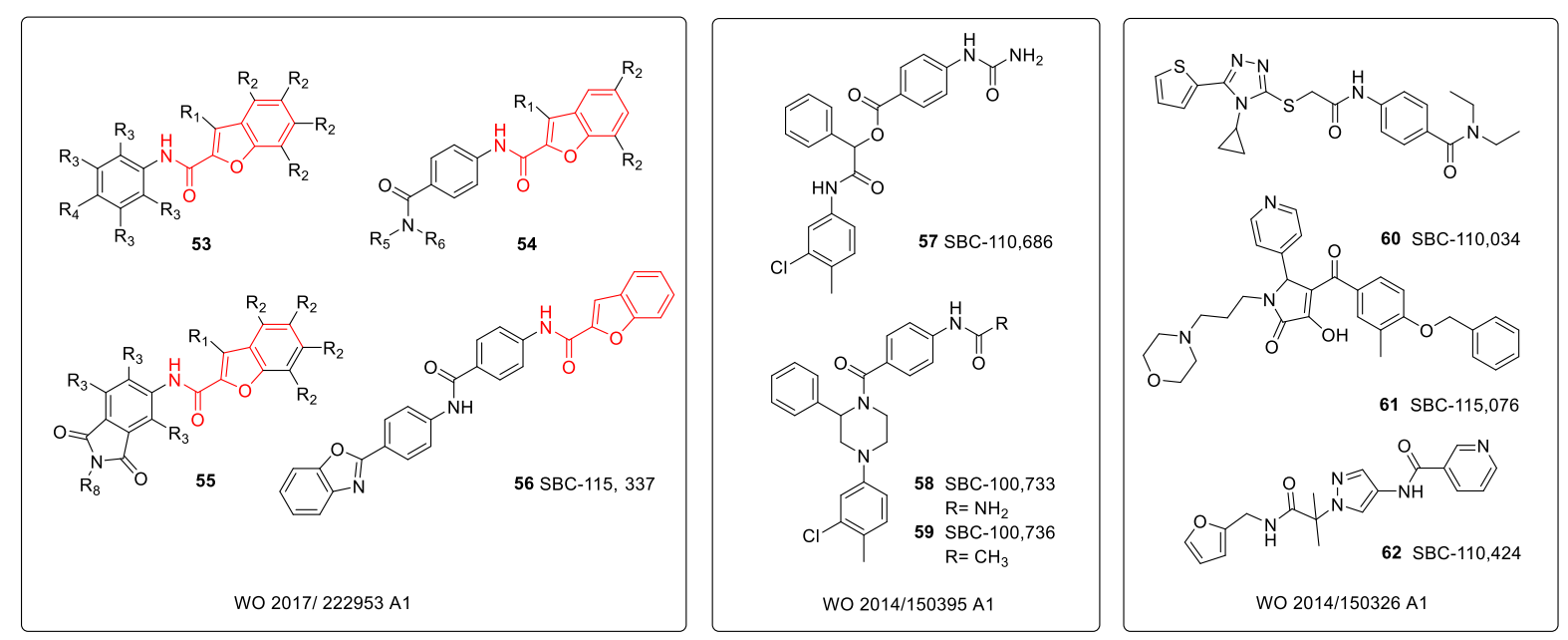

Figure 11. Markush structures and representative compounds from Shifa.

Many of the surfaces involved in the PPI are rather flat, making the development of small organic compounds to disrupt is difficult. However, most of the binding energy for the association of the two proteins is contributed by a few "hot spots" that can potentially be disrupted with small molecules. A group from Temple University disclosed a robust virtual screening method for the discovery of small molecules that bind PCSK9 and block its binding to the LDLR (Figure 12) (WO 2016/040305 A1).[142] Approximately 1 million drug-like compounds and over 400k large compounds $(\mathrm{MW}>500)$ from ZINC databases were processed with screening campaigns, and eleven compounds were finally identified as lead hits. Coincidentally, some of these compounds have already been disclosed by the Shifa Biomedical Corporation. Further SAR studies and lead optimization based on the pyrazoles, represented by SBC-110,424 (62, Figure 12), and the 4-hydroxy-5-oxopyrroles, represented by SBC-115,076 (61), have been facilitated and accelerated by docking poses, but the results were not reported in detail in this patent. The detailed virtual screening process disclosed by Temple University for the development of small molecules blocking the PPI between PCSK9 and LDLR provided a reference to future research. 



Figure 12. Virtual screening method used to identify small molecules blocking the binding of PCSK9 to LDLR.

In 2014, the SRX Cardio LLC described a set of synthetic peptides of 3-8 amino acids as allosteric inhibitors of PCSK9 (WO 2014/127316 A2).[143] These compounds were reported to bind and alter the conformation of the PCSK9 protein, changing the kinetics of the interaction between PCSK9 and LDLR. The most efficacious peptide is SRX55 (63, Figure 13a). Improved peptides were then designed by incorporating a negatively charged polar group to obtain better drug-like properties, and SRX60 (64), which contains a phosphate group, is a typical example. Two year later, the chemists from the SRX Cardio LLC simplified these peptides into small organic compounds, and negatively charged polar groups such as phosphate and tetrazole were retained (65-68, Figure 13b, WO 2016/029037 A1).[144] Considerable biological data were presented in this patent, including direct binding assays measured using backscatter interferometry. The most potent compound presented was SRX200 (66), which bound to recombinant human PCSK9 with a measured $K_{\mathrm{d}}$ of $24 \pm 8 \mathrm{nM}$. Allosteric modulation of PPI by small molecules binding to an allosteric site provides potential way forward for the difficult targets without apparent deep pockets in the interface.[145] Developing allosteric inhibitors of PCSK9 which bind to the allosteric site of PCSK9 and alter the 
kinetics of the interaction between PCSK9 and LDLR seems to be a promising strategy identified by SRX Cardio LLC in this patent, which is worth following up.
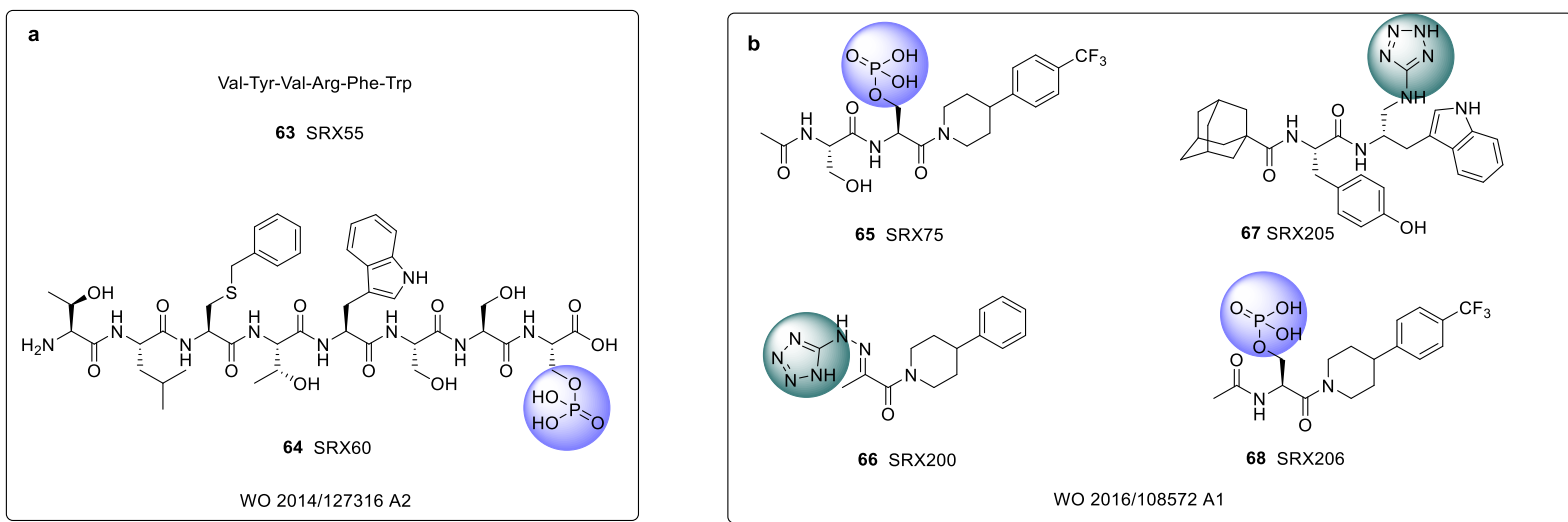

Figure 13. Representative compounds from SRX Cardio LLC. (a) Synthetic peptides; (b) Small organic compounds simplified from peptides.

\subsection{Small molecules inhibiting PCSK9 expression}

Recently, inventors from Paris have observed that steady-state PCSK9 mRNA levels in mouse primary hepatocytes surprisingly decreased by more than $90 \%$ after $24 \mathrm{~h}$ of treatment with anticancer agents IBET-151 (69, 2.5 $\mu \mathrm{M})$ and JQ1 (70, $2.0 \mu \mathrm{M})$ (Figure 14a).[146] Interestingly, JQ1 and IBET-151 are potent, highly specific, competitive inhibitors of acetyl-lysine for the bromodomain and extraterminal (BET) family of bromodomains (BRDs). These results show that BRD inhibitors may represent a novel way to inhibit PCSK9 expression and hence reduce circulating LDL levels; however, the detailed mechanism of the invention was not disclosed.
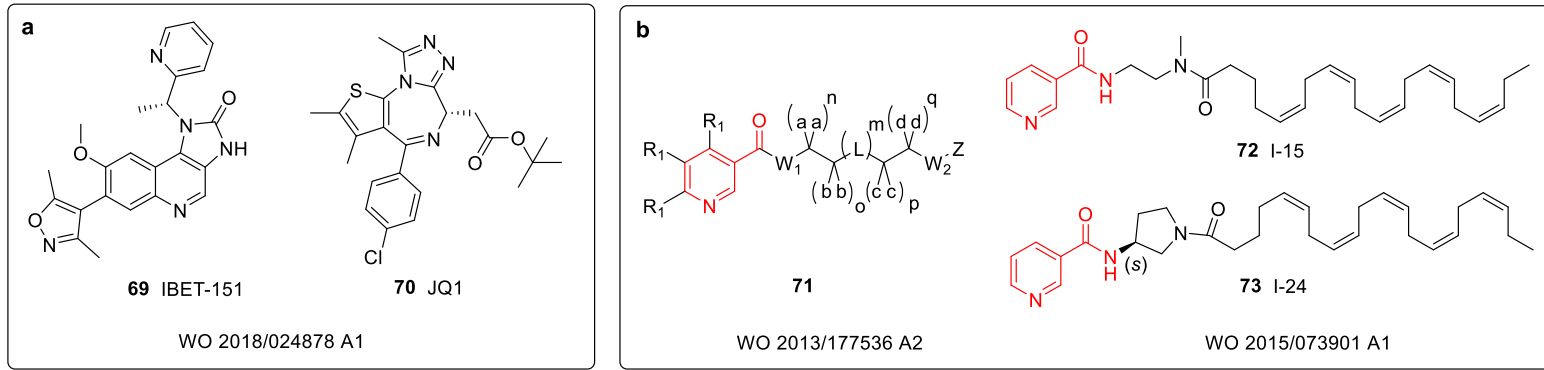

Figure 14. Small molecules inhibiting PCSK9 expression. (a) Structure of JQ-1 and IBET-151; (b) Markush structure and representative compounds of fatty acid niacin conjugates. 
A set of novel fatty acid niacin conjugates (71) was disclosed by Catabasis Pharmaceuticals in 2013 for treating or preventing metabolic diseases by inhibiting the production or lowering the serum levels of PCSK9 protein (WO 2013/177536 A2).[147] Two years later, a more extensive patent presenting significant activities for two selected compounds (72 and 73, Figure 14b) was disclosed by the same company (WO 2015/073901 A1).[148] The surprising benefit of these $N$-alkylated fatty acid niacin conjugates is their ability to preferentially accumulate in the liver rather than other tissues. In 2016, the biological data supporting this result appeared in the scientific literature.[149] The fatty acid niacin conjugate $\mathbf{7 2}$ has been advanced into clinical trials to evaluate its effect on various lipid parameters.

Chengdu Bestchiralbio Pharmaceuticals has also patented a set of substituted nitrogen-containing heterocyclic derivatives as inhibitors of PCSK9 that down regulate PCSK9 expression at the mRNA level. At least 166 analogs are exemplified in WO 2016/107603 A1, and at least 87 analogs are exemplified in WO 2016/107602 A1.[150, 151] Most of the compounds in these series have a substituted piperazine or piperidine ring. Figure 15a shows the in vivo assays of typical potent compounds in these two patents $(\mathbf{7 4}, \mathbf{7 5})$. In addition, these compounds activated AMPK and can be used to treat type 2 diabetes.


Figure 15. Representative compounds from (a) Chengdu Bestchiralbio; (b) Broad Institute; (c) Amorchem Holdings. 
The Broad Institute described small molecules that modulate hepatic cholesterol by downregulating the expression levels of PCSK9 (inhibit the expression of PCSK 9 mRNA and secretion of PCSK9 protein) and upregulating the expression level of Tribbles homolog 1 (TRIB1) (WO 2014/028946 A2, and WO 2016/100711 A1).[152, 153] The general formula (76, Figure 15b) is exemplified in 148 explicit examples. Compound $\mathbf{7 7}$ is the reference compound representing the series and was found to downregulate PCSK9 with an $\mathrm{EC}_{50}$ of $0.36 \mu \mathrm{M}$, as monitored by quantitative polymerase chain reaction (qPCR) analysis.

At least 91 aminoacid-based compounds have been disclosed by a worker from AmorChem Holdings Inc., for preventing or treating LDL-C-related disease (WO 2014/139008 A1).[154] Compounds of the invention were screened using biological PCSK9-based assays, and at least 24 compounds were identified to inhibit PCSK9 secretion in a dose-dependent manner. Compounds 78-80 were typical examples (Figure 15c). However, the toxicity of some examples containing boric acid demands attention due to the potential carcinogenicity.[155]

\subsection{Additional patents}

Since 2011, Cadila Healthcare Pharmaceuticals have continuously published five patents (WO 2011/051961 A1, WO 2012/090220 A1, WO 2013/132509 A1, WO 2014/002105 A1, and WO 2014/002106 A1) claiming compounds for the treatment of dyslipidemia and related diseases. The initial Markush structure in these patents is extremely broad, but all of the compounds contain a substituted tetrahydropyran moiety. Although a PCSK9/LDLR in vitro binding assay was performed to support the claimed formulas, the mechanism that is responsible for the hypocholesterolemic effect of these compounds has not yet been fully clarified in all these patents.[156-160]

In 2018, researchers from Merck disclosed PCSK9 allosteric binding compounds bearing tetrahydroisoquinoline moiety (81, Figure 16).[161] These PCSK9 allosteric binders capable of stabilizing PCSK9 may stabilize PCSK9 in an inactive conformation, a conformation that inhibits PCSK9's ability to bind to the LDLR, increasing the cell 
surface function of LDLR. In addition, some compounds in this invention exhibit the ability to lower steady state concentrations of both the pro and mature forms of PCSK9. For example, compound $\mathbf{8 2}$ was found to degrade mature PCSK9 level with $\mathrm{DC}_{50}$ value of $1.05 \mu \mathrm{M}$. Interestingly, some PCSK9 allosteric binders specifically bind PCSK9 at a unique site that does not interfere with the binding of PCSK9 with the LDLR, can be used, inter alia, in the detection, quantitation and imaging of PCSK9 in a sample when coupled with a detectable marker, e.g. a fluorescence probe or biotin $(\mathbf{8 3}, \mathbf{8 4})$. These PCSK9 allosteric binding compounds disclosed by Merck have different functions when binding to PCSK9 at different allosteric sites, extending the capability of allosteric modulators. However, no further information about these allosteric sites was disclosed in this patent.
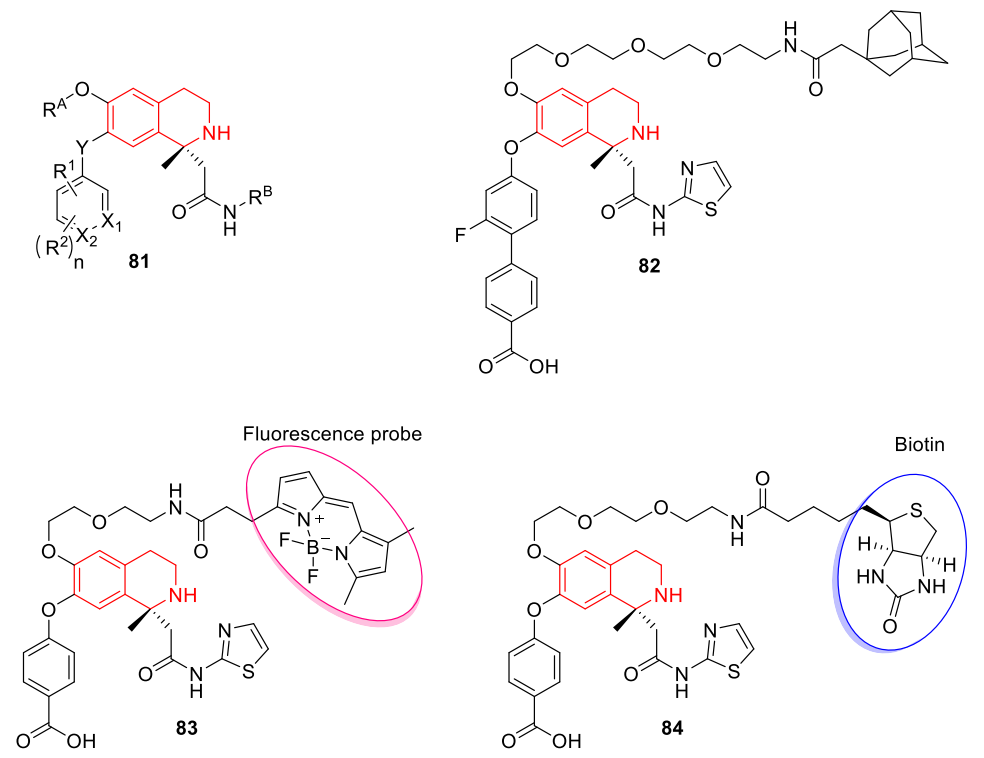

Figure 16. Markush structure of PCSK9 allosteric binders and representative labeling probes from Merck.

It is noteworthy that some compounds protected in patents have been reported in scientific journals and have been discussed in the first section of this review (WO2018/054959 A1, WO2018/053517 A1, WO2016/108572 A2, WO2014/170786 A1, WO2016/055901 A1, and WO2014/005224 A1). Finally, it is difficult to obtain a comprehensive view of all small-molecule PCSK9 inhibitors reported in non-English patents due to language barriers (WO 2016/021706 A1, WO 2014/017569 A1, and WO 
2013/137371 A1); thus, other patents related to molecules that target PCSK9 might exist.

\section{Table 2}

Selected international patent applications related to small-molecule inhibitors of PCSK9.

\begin{tabular}{|c|c|c|c|c|c|}
\hline NO. & Title & Mechanism & $\begin{array}{l}\text { Publication } \\
\text { number }\end{array}$ & $\begin{array}{l}\text { Publication } \\
\text { date }\end{array}$ & Applicant(s) \\
\hline 1 & Methods of inhibiting PCSK9 & Not provided & WO2018/129205 A1 & $12-07-2018$ & $\begin{array}{l}\text { The Trustees of } \\
\text { Dartmouth College }\end{array}$ \\
\hline 2 & $\begin{array}{l}\text { Compounds for treatment of } \\
\text { lipoprotein metabolism disorders }\end{array}$ & $\begin{array}{l}\text { Heparin analogues } \\
\text { prevent PCSK9/LDLR } \\
\text { complex formation }\end{array}$ & WO2018/054959 A1 & 29-03-2018 & AARHUS Universitet \\
\hline 3 & $\begin{array}{l}\text { Substituted 1-methyl-1,2,3,4- } \\
\text { tetrahydroisoquiniline molecules as } \\
\text { PCSK9 allosteric binders }\end{array}$ & $\begin{array}{l}\text { PCSK9 allosteric } \\
\text { binding compounds }\end{array}$ & WO2018/057409 A1 & 29-03-2018 & $\begin{array}{l}\text { Merck Sharp \& Dohme } \\
\text { Corp. }\end{array}$ \\
\hline 4 & $\begin{array}{l}\text { Inhibitors of LDLR-PCSK9 protein- } \\
\text { protein interaction and methods of } \\
\text { their use }\end{array}$ & $\begin{array}{l}\text { Disrupt the PPI } \\
\text { between PCSK9 and } \\
\text { LDLR }\end{array}$ & WO2018/053517 A1 & $22-03-2018$ & $\begin{array}{l}\text { The Texas A\&M } \\
\text { University }\end{array}$ \\
\hline 5 & $\begin{array}{l}\text { Methods and compositions for } \\
\text { reducing PCSK9 expression }\end{array}$ & $\begin{array}{l}\text { Inhibit } \quad \text { PCSK9 } \\
\text { expression }\end{array}$ & WO2018/024878 A1 & 08-02-2018 & $\begin{array}{l}\text { Centre National de la } \\
\text { Recherche } \\
\text { Scientifique (CNRS); } \\
\text { Institut National de la } \\
\text { Santé et de la } \\
\text { Recherche Médicale } \\
\text { (INSERM); } \\
\text { Université } \\
\text { Descartes }\end{array}$ \\
\hline 6 & $\begin{array}{l}\text { Antiproprotein convertase subtilisin } \\
\text { kexin type } 9 \text { (anti-PCSK9) } \\
\text { compounds and methods of using the } \\
\text { same in the treatment and/or } \\
\text { prevention of cardiovascular diseases }\end{array}$ & $\begin{array}{l}\text { Modulate the } \\
\text { physiological action of } \\
\text { PCSK9, including its } \\
\text { interaction with the } \\
\text { LDLR }\end{array}$ & WO2017/222953 A1 & $28-12-2017$ & $\begin{array}{l}\text { Shifa Biomedical } \\
\text { Corporation }\end{array}$ \\
\hline 7 & $\begin{array}{l}\text { Phenyl [a]indole[2,3-g]quinolizine } \\
\text { compounds, preparation method } \\
\text { therefor, pharmaceutical } \\
\text { composition, and applications thereof }\end{array}$ & Not provided & WO2017/167202 A1 & 29-03-2017 & $\begin{array}{l}\text { Shanghai Institute of } \\
\text { Materia Medica, } \\
\text { Chinese Academy of } \\
\text { Sciences }\end{array}$ \\
\hline 8 & $\begin{array}{l}\text { Phenylpiperazine proprotein } \\
\text { convertase subtilisin/kexin type } 9 \\
\text { (PCSK9) modulators and their use }\end{array}$ & $\begin{array}{l}\text { Bind to PCSK9 and } \\
\text { alter the conformation } \\
\text { of the protein }\end{array}$ & WO2017/034997 A1 & 02-03-2017 & $\begin{array}{l}\text { Portola } \\
\text { Pharmaceuticals, Inc. }\end{array}$ \\
\hline
\end{tabular}




\begin{tabular}{|c|c|c|c|c|c|}
\hline 9 & $\begin{array}{l}\text { Composition and methods of use of } \\
\text { tetrahydroisoquinoline small } \\
\text { molecules to bind and modulate } \\
\text { PCSK9 protein activity }\end{array}$ & $\begin{array}{l}\text { Bind to PCSK9 and } \\
\text { alter the conformation } \\
\text { of the protein }\end{array}$ & WO2017/034990 A1 & 02-03-2017 & $\begin{array}{l}\text { Portola } \\
\text { Pharmaceuticals, Inc. }\end{array}$ \\
\hline 10 & $\begin{array}{l}\text { Composition and methods of use of } \\
\text { novel phenylalanine small organic } \\
\text { compounds to directly modulate } \\
\text { PCSK9 protein activity }\end{array}$ & $\begin{array}{l}\text { Bind to PCSK9 and } \\
\text { alter the conformation } \\
\text { of the protein }\end{array}$ & WO2017/034994 A1 & 02-03-2017 & $\begin{array}{l}\text { Portola } \\
\text { Pharmaceuticals, Inc. }\end{array}$ \\
\hline 11 & $\begin{array}{l}\text { Composition for preventing and } \\
\text { treating cholesterol-related diseases }\end{array}$ & $\begin{array}{l}\text { Inhibit the linkage } \\
\text { between PCSK9 and } \\
\text { LDLR }\end{array}$ & WO2016/108572 A2 & 07-07-2016 & $\begin{array}{l}\text { Industry-ACA-Demic } \\
\text { Cooperation } \\
\text { Foundation } \\
\text { Yonsei University }\end{array}$ \\
\hline 12 & $\begin{array}{l}\text { Substituted nitrogen-containing } \\
\text { heterocyclic derivatives and } \\
\text { applications thereof }\end{array}$ & $\begin{array}{l}\text { Inhibit } \quad \text { PCSK9 } \\
\text { expression }\end{array}$ & WO2016/107603 A1 & 07-07-2016 & $\begin{array}{l}\text { Chengdu Bestchiralbio } \\
\text { LLC. }\end{array}$ \\
\hline 13 & $\begin{array}{l}\text { Substituted nitrogen heterocyclic } \\
\text { derivatives and use thereof }\end{array}$ & $\begin{array}{l}\text { Inhibit } \quad \text { PCSK9 } \\
\text { expression }\end{array}$ & WO2016/107602 A1 & 07-07-2016 & $\begin{array}{l}\text { Chengdu Bestchiralbio } \\
\text { LLC. }\end{array}$ \\
\hline 14 & $\begin{array}{l}\text { Modulators of hepatic lipoprotein } \\
\text { metabolism }\end{array}$ & $\begin{array}{l}\text { Inhibit the expression } \\
\text { of PCSK9 mRNA and } \\
\text { secretion of PCSK9 } \\
\text { protein }\end{array}$ & WO2016/100711 A1 & 23-06-2016 & $\begin{array}{l}\text { The Broad Institute, } \\
\text { Inc. }\end{array}$ \\
\hline 15 & Substituted amide compounds & $\begin{array}{l}\text { Inhibit } \quad \text { PCSK9 } \\
\text { translation }\end{array}$ & WO2016/055901 A1 & 14-04-2016 & Pfizer Inc. \\
\hline 16 & $\begin{array}{l}\text { PCSK9 inhibitors and methods of use } \\
\text { thereof }\end{array}$ & $\begin{array}{l}\text { Disrupt the PPI } \\
\text { between PCSK9 and } \\
\text { LDLR }\end{array}$ & WO2016/040305 A1 & $17-03-2016$ & $\begin{array}{l}\text { Temple University-of } \\
\text { the Commonwealth } \\
\text { System of Higher } \\
\text { Education }\end{array}$ \\
\hline 17 & $\begin{array}{l}\text { Composition and methods of use of } \\
\text { small molecules as binding ligands } \\
\text { for the modulation of proprotein } \\
\text { convertase subtilisin/kexin type } 9 \\
\text { (PCSK9) protein activity }\end{array}$ & $\begin{array}{l}\text { Alter the conformation } \\
\text { of the protein PCSK9 }\end{array}$ & WO2016/029037 A1 & $25-02-2016$ & SRX Cardio, LLC \\
\hline 18 & Fatty acid niacin conjugates & $\begin{array}{lr}\text { Inhibit } & \text { PCSK9 } \\
\text { expression } & \text { and/or } \\
\text { production } & \end{array}$ & $073901 \mathrm{~A} 1$ & $21-05-2015$ & $\begin{array}{l}\text { Catabasis } \\
\text { Pharmaceuticals, Inc. }\end{array}$ \\
\hline 19 & $\begin{array}{l}\text { N-piperidin-3-ylbenzamide } \\
\text { derivatives for treating } \\
\text { cardiovascular diseases }\end{array}$ & $\begin{array}{l}\text { Inhibit the translation } \\
\text { of PCSK9 mRNA to } \\
\text { protein }\end{array}$ & WO2014/170786 A1 & $23-10-2014$ & Pfizer Inc. \\
\hline 20 & $\begin{array}{l}\text { Small molecule modulators of } \\
\text { PCSK9 and methods of use thereof }\end{array}$ & $\begin{array}{l}\text { Inhibit } \\
\text { secretion }\end{array}$ & WO2014/139008 A1 & $18-09-2014$ & $\begin{array}{l}\text { Adaerata Limited } \\
\text { Partnership; } \\
\text { AmorChem Holdings } \\
\text { Inc. }\end{array}$ \\
\hline 21 & $\begin{array}{l}\text { Antiproprotein convertase subtilisin } \\
\text { kexin type } 9 \quad \text { (anti-PCSK9) }\end{array}$ & $\begin{array}{l}\text { Modulate the } \\
\text { physiological action of }\end{array}$ & WO2014/150326 A1 & $25-09-2014$ & $\begin{array}{l}\text { Shifa Biomedical } \\
\text { Corporation }\end{array}$ \\
\hline
\end{tabular}




\begin{tabular}{|c|c|c|c|c|c|}
\hline & $\begin{array}{l}\text { compounds and methods of using the } \\
\text { same in the treatment and/or } \\
\text { prevention of cardiovascular diseases }\end{array}$ & $\begin{array}{l}\text { PCSK9, including its } \\
\text { interaction with the } \\
\text { LDLR }\end{array}$ & & & \\
\hline 22 & $\begin{array}{l}\text { Anti-PCSK9 compounds and } \\
\text { methods for the treatment and/or } \\
\text { prevention of cardiovascular diseases }\end{array}$ & $\begin{array}{l}\text { Modulate the } \\
\text { physiological action of } \\
\text { PCSK9, including its } \\
\text { interaction with the } \\
\text { LDLR }\end{array}$ & WO2014/150395 A1 & $25-09-2014$ & $\begin{array}{l}\text { Shifa Biomedical } \\
\text { Corporation }\end{array}$ \\
\hline 23 & $\begin{array}{l}\text { Proprotein } \\
\text { subtilisin/kexin type } 9 \text { (PCSK9) } \\
\text { allosteric binding ligands to modulate } \\
\text { serum low density lipoprotein (LDL) } \\
\text { levels }\end{array}$ & $\begin{array}{l}\text { Alter the conformation } \\
\text { of the protein PCSK9 }\end{array}$ & WO2014/127316 A2 & $21-08-2014$ & SRX Cardio, LLC \\
\hline 24 & $\begin{array}{l}\text { Modulators of hepatic lipoprotein } \\
\text { metabolism }\end{array}$ & $\begin{array}{l}\text { Inhibit the expression } \\
\text { of PCSK9 mRNA and } \\
\text { secretion of PCSK9 } \\
\text { protein }\end{array}$ & WO2014/028946 A2 & $20-02-2014$ & $\begin{array}{l}\text { The Broad Institute, } \\
\text { INC. }\end{array}$ \\
\hline 25 & $\begin{array}{l}\text { Quercetin-3-glucoside and uses } \\
\text { thereof }\end{array}$ & $\begin{array}{l}\text { Increase the amount of } \\
\text { PCSK9 secreted by } \\
\text { hepatocyte cells }\end{array}$ & WO2014/005224 A1 & 09-01-2014 & $\begin{array}{l}\text { Mbikay Majambu } \\
\text { Sirois Francine } \\
\text { Chretien Michel } \\
\text { Mayne Janice }\end{array}$ \\
\hline 26 & $\begin{array}{l}\text { Novel compounds for the treatment } \\
\text { of dyslipidemia and related diseases }\end{array}$ & Not provided & WO2014/002106 A1 & 03-01-2014 & Healthcare \\
\hline 27 & $\begin{array}{l}\text { Compounds for the treatment of } \\
\text { dyslipidemia and other diseases }\end{array}$ & Not provided & WO2014/002105 A1 & 03-01-2014 & $\begin{array}{l}\text { Cadila Healthcare } \\
\text { Limited }\end{array}$ \\
\hline 28 & $\begin{array}{l}\text { Novel compounds for the treatment } \\
\text { of dyslipidemia and related diseases }\end{array}$ & Not provided & WO2013/132509 A1 & $12-03-2013$ & $\begin{array}{l}\text { Cadila } \\
\text { Limited }\end{array}$ \\
\hline 29 & $\begin{array}{l}\text { Methods of lowering proprotein } \\
\text { convertase subtilisin/kexin types } \\
\text { (PCSK9) }\end{array}$ & $\begin{array}{l}\text { Inhibit the production } \\
\text { of PCSK9 }\end{array}$ & WO2013/177536 A2 & $28-11-2013$ & $\begin{array}{l}\text { Catabasis } \\
\text { Pharmaceuticals, INC. }\end{array}$ \\
\hline 30 & $\begin{array}{l}\text { Heterocyclic compounds suitable for } \\
\text { the treatment of dyslipidemia }\end{array}$ & Not provided & WO2012/090220 A1 & 05-07-2012 & Healthcare \\
\hline 31 & $\begin{array}{l}\text { Compounds for the treatment of } \\
\text { dyslipidemia and related diseases }\end{array}$ & Not provided & WO2011/051961 A1 & $05-05-2011$ & $\begin{array}{l}\text { Cadila Healthcare } \\
\text { Limited }\end{array}$ \\
\hline 32 & $\begin{array}{l}\text { Berberine derivatives useful for } \\
\text { modulating lipid levels and their } \\
\text { methods of synthesis }\end{array}$ & $\begin{array}{l}\text { Inhibit } \\
\text { expression }\end{array}$ & WO2011/006000 A1 & $13-01-2011$ & $\begin{array}{l}\text { Liu Haiyan } \\
\text { Li Gaoping } \\
\text { Wang Junbo } \\
\text { Liu Jingwen }\end{array}$ \\
\hline 33 & $\begin{array}{l}\text { Corydaline derivatives useful for } \\
\text { reducing lipid levels }\end{array}$ & $\begin{array}{l}\text { Inhibit } \\
\text { expression }\end{array}$ & WO2010/075469 A1 & 01-07-2010 & $\begin{array}{l}\text { CVI Pharmaceuticals } \\
\text { Limited }\end{array}$ \\
\hline
\end{tabular}

\section{Potential strategies for the design of small molecules}


The search is on to develop small-molecule inhibitors of PCSK9, and some potential strategies or techniques that might be applied to the design of novel small-molecule PCSK9 inhibitors will be introduced in this section.

\subsection{Another binding site on PCSK9 for the design of small-molecule inhibitors}

The abovementioned characteristics of PCSK9 implied that developing small-molecule inhibitors based on the EGF(A)-binding site is difficult. Altering the conformation of PCSK9 by allosteric inhibitors has been successfully displayed by SRX Cardio LLC, but the relevant patents did not uncover the allosteric site. A recent study from the Kirchhofer group discovered a cryptic peptide-binding site next to the LDLR-binding site on PCSK9, which is possible for small molecules to target this site and inhibit LDLR binding by a steric mechanism.[162] The findings suggested that the P'-helix (Ser ${ }^{153}-$ Thr $^{162}$ of the catalytic domain) is intrinsically labile and adopts different conformational states; in the 'out' state, the groove becomes accessible for peptides to bind, which could antagonize LDLR binding by a steric mechanism. Grooved-binding antagonistic peptides that share sequence homology with the native P'-helix are potent PCSK9 inhibitors, affording a new strategy for the development of small molecules from these peptides to antagonize PCSK9.[163]

\subsection{Aptamers}

Aptamers are synthetic oligonucleotides or peptides that bind to a specific target molecule with high affinity. Aptamers are now used ubiquitously as binding agents for a broad range of applications.[164] They function similarly to mAbs, but have more advantages over antibodies. The fact that unmodified DNA or RNA aptamers have less chemical diversity than antibodies limits their wide application. Recently, a group from SomaLogic, Inc. reported the selection and identification of DNA aptamers in which one or both pyrimidines were replaced by side-chain-functionalized variants that bind and inhibit PCSK9 with dissociation constants similar to those of approved antibodies (evolocumab, $K_{\mathrm{D}}=8.0 \mathrm{pM}$, and alirocumab, $K_{\mathrm{D}}=0.58 \mathrm{nM}$ ).[165] Recently, Liu and co-workers developed a ligase-mediated DNA-templated polymerization and in vitro 
selection system, and diverse highly functionalized nucleic acid polymers (HFNAPS) were prepared. HFNAPs that bind PCSK9 were selected for further diversification and reselection, resulting in an improved PCSK9-binding HFNAP with a $K_{\mathrm{D}}$ of $3 \mathrm{nM}$, which potently inhibited the binding between PCSK9 and the LDLR. These studies shed light on designing extensively chemically functionalized aptamers as potential PCSK9 inhibitors.[166]

\subsection{Proteolysis-targeting chimera technology}

It seems from the current data that low PCSK9 function and LDL-C levels caused by PCSK9 inhibitors or LOF mutations did not trigger possible deleterious effects.[167] An extreme example comes from a patient who was a compound heterozygote for the Y142X and $\Delta \mathrm{R} 97$ LOF mutations, which disrupt the synthesis and processing/secretion of PCSK9, respectively. No additional adverse events were observed in this patient, although the levels of PCSK9 were below the limit of detection and the LDL-C level was as low as $14 \mathrm{mg} / \mathrm{dL}$.[167] RNA interference, antisense RNA and CRISPR-Cas9 techniques are often used to knock down the target protein, but proteolysis-targeting chimera (PROTAC) technology has recently been successfully applied to selective degradation of multiple protein targets other than PCSK9.[168] PROTAC methods utilize endogenous cellular quality control machinery by recruiting it to the target protein to induce its degradation. Thus, the targeted degradation of PCSK9 protein using PROTAC technology might be possible, although there have been no related reports in the literature.

\subsection{Targeting the signal transduction cascade}

Relatively little is known about the PCSK9 promoter. PCSK9 and LDLR are coregulated by SREBP-2.[169] Reducing the amount of PCSK9 mRNA by disrupting the SREBP pathway would be expected to down-regulate transcription of the LDLR gene, which would counteract a beneficial effect of lowering PCSK9 levels. The Kowa Company reported a new cholesteryl ester transfer protein (CETP) inhibitor, K-312, that suppressed PCSK9 expression through modulation of its transcription by 
decreasing SREBP levels, representing a novel strategy to reduce LDL-C.[170] Thus, with the development of the molecular biology of PCSK9, more signaling pathways and interconnected factors of PCSK9 will be unveiled and facilitate the search for new inhibitors of PCSK9 activity.[171] Several natural products have been widely reported to modulated PCSK9 levels without detailed mechanisms, and mechanism studies about these natural products may facilitate reveling the signaling pathways associated with PCSK9.

\section{Summary and future directions}

The cost of current PCSK9-blocking antibodies (\$US14,500 and \$US14,100 per year for evolocumab and alirocumab, respectively) has aroused a fierce debate, as only 15\% relative risk reduction resulted from these expensive antibodies.[172] The costeffectiveness ratio may be acceptable for patients currently with familial hypercholesterolemia, but for patients with conventional vascular disease, these antibodies are not so cost effective.[173, 174] The appeal of small-molecule inhibitors of PCSK9 over antibodies is rather clear, because you can achieve the same goal with only hundreds of dollars, let alone the potential for delivering the inhibitors via oral pills instead of injectable antibodies. In addition, despite antibodies perturbing the binding of PCSK9 to LDLR, by their nature, anti-PCSK9 mAbs are unable to modulate PCSK9 and LDL-C levels in an intermediate fashion, while the inhibition of PCSK9 synthesis by a small molecule could provide additional options for patients and physicians by offering different levels of inhibition to balance safety and efficacy. Thus, orally administrated small molecule is a preferred approach to inhibit PCSK9.

Base on the above descriptions, three strategies can be concluded that have been applied to inhibit PCSK9 with small molecules, including 1) preventing the binding of PCSK9 to LDLR; 2) interfering with the maturation and secretion processing or the biological function of PCSK9; and 3) inhibiting the synthesis and expression of PCSK9. Designing small molecules disrupting the PPI between PCSK9 and the LDLR is the most immediate strategy but also the toughest way to discover small-molecule PCSK9 inhibitors. The $K_{\mathrm{D}}$ for PCSK9/LDLR is in submicromolar level,[175] which makes 
small-molecule inhibitors targeting the relatively flat EGF(A)-binding site on PCSK9 quite challenging. The discovery of "hot spots" makes it possible to prevent the binding of PCSK9 to the LDLR directly; in addition, altering the conformation of PCSK9 (allosteric modulators) can also change the interactions between PCSK9 and LDLR, leading to reduced levels of circulating LDL-C.[176] However, considering the potent binding affinity between PCSK9 and LDLR, most of the currently reported inhibitors targeting the PPI between PCSK9 and LDLR directly may not be potent enough to disrupt the binding. Altering the conformation of PCSK9 by allosteric inhibitors or


PCSK9/LDLR interaction with small molecules in the future. Maturation and secretion processing are required for PCSK9 function, and a small-molecule inhibitor that interferes with these processes would block, suppress, and reduce PCSK9 biological activity or decrease the amount of mature, secreted PCSK9. However, few smallmolecule inhibitors have been reported that reduce LDL-C levels through this pathway. Transcription and translation of PCSK9 are controlled by many factors, and a small molecule targeting these factors would also reduce the synthesis and expression of PCSK9 protein. Many small-molecule inhibitors, like natural products, have been reported to reduce PCSK9 at the gene or protein levels, but their detailed mechanisms need further study. Cell-based HTS afforded opportunities to overtake PPI-based strategies. In addition, mechanism of action studies of compounds from HTS or natural products might disclose novel mechanisms and facilitate the discovery of smallmolecule PCSK9 inhibitors.

Up to date, antibody targeting mature PCSK9 is the most advanced modality, other points of intervention and modalities have also been widely reported. In all cases, small molecule progress has lagged behind. Although researchers have dabbled with the discovery of PCSK9 inhibitors, no significant progress toward small-molecule PCSK9 inhibitors has been made up to date. In recent five years, great efforts have been made to develop small-molecular PCSK9 inhibitors. This review, which highlights a few of the recent advances in small-molecule PCSK9 inhibitors, is a witness to the growing interest for and importance of this field. A pill that inhibits PCSK9 is "a Holy Grail" in 
the world of lowering LDL-C, and many companies and institutions are struggling to commercialize the first PCSK9 small-molecular inhibitors and win the chance to build a franchise in what is expected to be a blockbuster. Nevertheless, "a Holy Grail" is still at the top of the mountain, waiting for anyone who is keen and ambitious enough to pluck it.

\section{References}

[1] C.G. Global, regional, and national age-sex specific mortality for 264 causes of death, 1980-2016: a systematic analysis for the global burden of disease study 2016, Lancet 390 (2017) 1151-1210.

[2] M.G. Silverman, B.A. Ference, K. Im, S.D. Wiviott, R.P. Giugliano, S.M. Grundy, E. Braunwald, M.S. Sabatine, Association between lowering LDL-C and cardiovascular risk reduction among different therapeutic interventions: a systematic review and meta-analysis, Jama 316 (2016) 1289-1297.

[3] R.K. Wadhera, D.L. Steen, I. Khan, R.P. Giugliano, J.M. Foody, A review of low-density lipoprotein cholesterol, treatment strategies, and its impact on cardiovascular disease morbidity and mortality, J. Clin. Lipidol. 10 (2016) 472-489.

[4] R. Collins, C. Reith, J. Emberson, J. Armitage, C. Baigent, L. Blackwell, R. Blumenthal, J. Danesh, G.D. Smith, D. DeMets, Interpretation of the evidence for the efficacy and safety of statin therapy, Lancet 388 (2016) 2532-2561.

[5] L. Perez de Isla, R. Alonso, G.F. Watts, N. Mata, A. Saltijeral Cerezo, O. Muniz, F. Fuentes, J.L. Diaz-Diaz, R. de Andres, D. Zambon, P. Rubio-Marin, M.A. Barba-Romero, P. Saenz, J.F. Sanchez Munoz-Torrero, C. Martinez-Faedo, J.P. Miramontes-Gonzalez, L. Badimon, P. Mata, Attainment of LDL-Cholesterol Treatment Goals in Patients With Familial Hypercholesterolemia: 5-Year SAFEHEART Registry Follow-Up, J. Am. Coll. Cardiol. 67 (2016) 1278-1285.

[6] A.L. Mammen, Statin-associated autoimmune myopathy, N. Engl. J. Med. 374 (2016) 664-669.

[7] Y.J. Shimada, C.P. Cannon, PCSK9 (Proprotein convertase subtilisin/kexin type 9) inhibitors: past, present, and the future, Eur. Heart J. 36 (2015) 2415-2424.

[8] T.A. Lagace, PCSK9 and LDLR degradation: regulatory mechanisms in circulation and in cells, Curr. Opin. Lipidol. 25 (2014) 387-393. 
[9] R.P. Giugliano, M.S. Sabatine, Are PCSK9 inhibitors the next breakthrough in the cardiovascular field? J. Am. Coll. Cardiol. 65 (2015) 2638-2651.

[10] J.G. Robinson, M. Farnier, M. Krempf, J. Bergeron, G. Luc, M. Averna, E.S. Stroes, G. Langslet, F.J. Raal, M. El Shahawy, Efficacy and safety of alirocumab in reducing lipids and cardiovascular events, N. Engl. J. Med. 372 (2015) 1489-1499.

[11] M.S. Sabatine, R.P. Giugliano, A.C. Keech, N. Honarpour, S.D. Wiviott, S.A. Murphy, J.F. Kuder, H. Wang, T. Liu, S.M. Wasserman, Evolocumab and clinical outcomes in patients with cardiovascular disease, N. Engl. J. Med. 376 (2017) 1713-1722.

[12] R.P. Giugliano, F. Mach, K. Zavitz, C. Kurtz, K. Im, E. Kanevsky, J. Schneider, H. Wang, A. Keech, T.R. Pedersen, Cognitive function in a randomized trial of evolocumab, N. Engl. J. Med. 377 (2017) 633-643.

[13] J.G. Robinson, R.S. Rosenson, M. Farnier, U. Chaudhari, W.J. Sasiela, L. Merlet, K. Miller, J.J. Kastelein, Safety of very low low-density lipoprotein cholesterol levels with alirocumab: pooled data from randomized trials, J. Am. Coll. Cardiol. 69 (2017) 471-482.

[14] E.A. Stein, S. Mellis, G.D. Yancopoulos, N. Stahl, D. Logan, W.B. Smith, E. Lisbon, M. Gutierrez, C. Webb, R. Wu, Effect of a monoclonal antibody to PCSK9 on LDL cholesterol, N. Engl. J. Med. 366 (2012) 1108-1118

[15] E.P. Navarese, M. Kołodziejczak, V. Schulze, P.A. Gurbel, U. Tantry, Y. Lin, M. Brockmeyer, D.E. Kandzari, J.M. Kubica, R.B. D'agostino, Effects of proprotein convertase subtilisin/kexin type 9 antibodies in adults with hypercholesterolemia: a systematic review and meta-analysis, Ann. Intern. Med. 163 (2015) 40-51.

[16] R. Chaudhary, J. Garg, N. Shah, A. Sumner, PCSK9 inhibitors: A new era of lipid lowering therapy, World J. Cardiol. 9 (2017) 76-91.

[17] A.F. Schmidt, L.S. Pearce, J.T. Wilkins, J.P. Overington, A.D. Hingorani, J.P. Casas, PCSK9 monoclonal antibodies for the primary and secondary prevention of cardiovascular disease, Cochrane. Database Syst. Rev. 4 (2017) CD011748.

[18] D.S. Kazi, A.E. Moran, P.G. Coxson, J. Penko, D.A. Ollendorf, S.D. Pearson, J.A. Tice, D. Guzman, K. Bibbins-Domingo, Cost-effectiveness of PCSK9 inhibitor therapy in patients with heterozygous familial hypercholesterolemia or atherosclerotic cardiovascular disease, Jama 316 (2016) 743-753. 
[19] D. Pettersen, O. Fjellström, Small molecule modulators of PCSK9-a literature and patent overview, Bioorg. Med. Chem. Lett. 28 (2018) 1155-1160.

[20] N.G. Seidah, S. Benjannet, L. Wickham, J. Marcinkiewicz, S.B. Jasmin, S. Stifani, A. Basak, A. Prat, M. Chrétien, The secretory proprotein convertase neural apoptosis-regulated convertase 1 (NARC1): liver regeneration and neuronal differentiation, Proc. Natl. Acad. Sci. U. S. A. 100 (2003) 928-933. [21] A.W. Artenstein, S.M. Opal, Proprotein convertases in health and disease, N. Engl. J. Med. 365 (2011) 2507-2518.

[22] F. Du, Y. Hui, M. Zhang, M.F. Linton, S. Fazio, D. Fan, Novel domain interaction regulates secretion of proprotein convertase subtilisin/kexin type 9 (PCSK9) protein, J. Biol. Chem. 286 (2011) 43054-43061.

[23] S. Naureckiene, L. Ma, K. Sreekumar, U. Purandare, C.F. Lo, Y. Huang, L.W. Chiang, J.M. Grenier, B.A. Ozenberger, J.S. Jacobsen, Functional characterization of Narc 1, a novel proteinase related to proteinase K, Arch. Biochem. Biophys. 420 (2003) 55-67.

[24] S. Benjannet, D. Rhainds, R. Essalmani, J. Mayne, L. Wickham, W. Jin, M.-C. Asselin, J. Hamelin, M. Varret, D. Allard, NARC-1/PCSK9 and its natural mutants zymogen cleavage and effects on the low density lipoprotein (LDL) receptor and LDL cholesterol, J. Biol. Chem. 279 (2004) 48865-48875.

[25] N.G. Seidah, A. Prat, The biology and therapeutic targeting of the proprotein convertases, Nat. Rev. Drug Discov. 11 (2012) 367-383.

[26] H.J. Kwon, T.A. Lagace, M.C. McNutt, J.D. Horton, J. Deisenhofer, Molecular basis for LDL receptor recognition by PCSK9, Proc. Natl. Acad. Sci. U. S. A. 105 (2008) 1820-1825.

[27] M. Abifadel, M. Varret, J.-P. Rabès, D. Allard, K. Ouguerram, M. Devillers, C. Cruaud, S. Benjannet, L. Wickham, D. Erlich, Mutations in PCSK9 cause autosomal dominant hypercholesterolemia, Nat. Genet. 34 (2003) 154-156.

[28] H.J. Kwon, T.A. Lagace, M.C. McNutt, J.D. Horton, J. Deisenhofer, Molecular basis for LDL receptor recognition by PCSK9, Proc. Natl. Acad. Sci. U. S. A. 105 (2008) 1820-1825.

[29] M.S. Brown, J.L. Goldstein, A receptor-mediated pathway for cholesterol homeostasis, Science 232 (1986) 34-47.

[30] S. Benjannet, Y.G.L. Saavedra, J. Hamelin, M.-C. Asselin, R. Essalmani, A. Pasquato, P. Lemaire, G. Duke, B. Miao, F. Duclos, Effects of the prosegment and pH on the activity of PCSK9: evidence for additional processing events, J. Biol. Chem. 285 (2010) 40965-40978. 
[31] Y.-W. Qian, R.J. Schmidt, Y. Zhang, S. Chu, A. Lin, H. Wang, X. Wang, T.P. Beyer, W.R. Bensch, W. Li, Secreted PCSK9 downregulates low density lipoprotein receptor through receptor-mediated endocytosis, J. Lipid. Res. 48 (2007) 1488-1498.

[32] J.D. Horton, J.C. Cohen, H.H. Hobbs, PCSK9: a convertase that coordinates LDL catabolism, J. Lipid. Res. 50 (2009) S172-S177.

[33] N.G. Seidah, New developments in proprotein convertase subtilisin-kexin 9's biology and clinical implications, Curr. Opin. Lipidol. 27 (2016) 274-281.

[34] G. Lambert, B. Sjouke, B. Choque, J.J. Kastelein, G.K. Hovingh, The PCSK9 decade thematic review series: new lipid and lipoprotein targets for the treatment of cardiometabolic diseases, J. Lipid. Res. 53 (2012) 2515-2524.

[35] N.G. Seidah, PCSK9 as a therapeutic target of dyslipidemia, Expert Opin. Ther. Targets 13 (2009) 19-28.

[36] A. Mullard, Nine paths to PCSK9 inhibition, Nat. Rev. Drug. Discov. 16 (2017) 299-301.

[37] R.M. Ridker, J. Revkin, P. Amarenco, R. Brunell, M. Curto, F. Civeira, M. Flather, R.J. Glynn, J. Gregoire, J.W. Jukema, Y. Karpov, J.J.P. Kastelein, W. Koenig, A. Lorenzatti, P. Manga, U. Masiukiewicz, M. Miller, A. Mosterd, J. Murin, J.C. Nicolau, S. Nissen, P. Ponikowski, R.D. Santos, P.F. Schwartz, H. Soran, H. White, R.S. Wright, M. Vrablik, C. Yunis, C.L. Shear, J.C. Tardif, Cardiovascular efficacy and safety of bococizumab in hight-risk patients, N. Engl. J. Med. 376 (2017) 1527-1539.

[38] J.J. Kastelein, S.E. Nissen, D.J. Rader, G.K. Hovingh, M.-D. Wang, T. Shen, K.A. Krueger, Safety and efficacy of LY3015014, a monoclonal antibody to proprotein convertase subtilisin/kexin type 9 (PCSK9): a randomized, placebo-controlled Phase 2 study, Pharm. Res. 37 (2016) 1360-1369.

[39] T. Shen, D.E. James, K.A. Krueger, Population Pharmacokinetics (PK) and Pharmacodynamics (PD) Analysis of LY3015014, a Monoclonal Antibody to Protein Convertase Subtilisin/Kexin Type 9 (PCSK9) in Healthy Subjects and Hypercholesterolemia Patients, Pharm. Res. 34 (2017) 185-192.

[40] A. Baruch, S. Mosesova, J.D. Davis, N. Budha, A. Vilimovskij, R. Kahn, K. Peng, K.J. Cowan, L.P. Harris, T. Gelzleichter, Effects of RG7652, a monoclonal antibody against PCSK9, on LDL-C, LDL-C subfractions, and inflammatory biomarkers in patients at high risk of or with established coronary heart disease (from the phase 2 EQUATOR Study), Am. J. Cardiol. 119 (2017) 1576-1583. 
[41] A. Baruch, D. Luca, R.S. Kahn, K.J. Cowan, M. Leabman, N.R. Budha, C.P. Chiu, Y. Wu, D. Kirchhofer, A. Peterson, A phase 1 study to evaluate the safety and LDL cholesterol-lowering effects of RG7652, a fully human monoclonal antibody against proprotein convertase subtilisin/kexin type 9, Clin . Cardiol. 40 (2017) 503-511.

[42] Y. Zhang, C. Eigenbrot, L. Zhou, S. Shia, W. Li, C. Quan, J. Tom, P. Moran, P. Di Lello, N.J. Skelton, Identification of a small peptide that inhibits PCSK9 protein binding to the low density lipoprotein receptor, J. Biol. Chem. 289 (2014) 942-955.

[43] E.P. van Poelgeest, M.R. Hodges, M. Moerland, Y. Tessier, A.A. Levin, R. Persson, M.W. Lindholm, K. Dumong Erichsen, H. Orum, A.F. Cohen, J. Burggraaf, Antisense-mediated reduction of proprotein convertase subtilisin/kexin type 9 (PCSK9): a first-in-human randomized, placebo-controlled trial, Brit. J. Clin. Pharmaco. 80 (2015) 1350-1361.

[44] Safety Study of BMS-844421 for Treatment of Hypercholesterolemia. https://clinicaltrials.gov/ct2/show/NCT01082562?term=BMS-844421\&rank=1.

[45] A First In Human Study to Assess CiVi007 in Subjects With an Elevated LDL-Cholesterol Level. https://clinicaltrials.gov/ct2/show/NCT03427710?term=Civi-007\&rank=1.

[46] K.K. Ray, U. Landmesser, L.A. Leiter, D. Kallend, R. Dufour, M. Karakas, T. Hall, R.P. Troquay, T. Turner, F.L. Visseren, Inclisiran in patients at high cardiovascular risk with elevated LDL cholesterol, N. Engl. J. Med. 376 (2017) 1430-1440.

[47] K. Fitzgerald, S. White, A. Borodovsky, B.R. Bettencourt, A. Strahs, V. Clausen, P. Wijngaard, J.D. Horton, J. Taubel, A. Brooks, A highly durable RNAi therapeutic inhibitor of PCSK9, N. Engl. J. Med. 376 (2017) 41-51.

[48] T. Mitchell, G. Chao, D. Sitkoff, F. Lo, H. Monshizadegan, D. Meyers, S. Low, K. Russo, R. DiBella, F. Denhez, Pharmacologic profile of the Adnectin BMS-962476, a small protein biologic alternative to PCSK9 antibodies for low-density lipoprotein lowering, J. Pharmacol. Exp. Ther. 350 (2014) 412-424. [49] Y. Masuda, S. Yamaguchi, C. Suzuki, T. Aburatani, Y. Nagano, R. Miyauchi, E. Suzuki, N. Yamamura, K. Nagatomo, H. Ishihara, Generation and Characterization of a Novel Small Biologic Alternative to Proprotein Convertase Subtilisin/Kexin Type 9 (PCSK9) Antibodies, DS-9001a, Albumin Binding Domain-Fused Anticalin Protein, J. Pharmacol. Exp. Ther. 365 (2018) 368-378.

[50] C. Landlinger, M.G. Pouwer, C. Juno, J.W. van der Hoorn, E.J. Pieterman, J.W. Jukema, G. Staffler, H.M. Princen, G. Galabova, The AT04A vaccine against proprotein convertase subtilisin/kexin type 9 
reduces total cholesterol, vascular inflammation, and atherosclerosis in APOE*3Leiden.CETP mice, Eur. Heart J. 38 (2017) 2499-2507.

[51] Q. Ding, A. Strong, K.M. Patel, S.-L. Ng, B.S. Gosis, S.N. Regan, C.A. Cowan, D.J. Rader, K. Musunuru, Permanent alteration of PCSK9 with in vivo CRISPR-Cas9 genome editing, Circ. Res. 115 (2014) 488-492.

[52] F.A. Ran, L. Cong, W.X. Yan, D.A. Scott, J.S. Gootenberg, A.J. Kriz, B. Zetsche, O. Shalem, X. Wu, K.S. Makarova, In vivo genome editing using Staphylococcus aureus Cas9, Nature 520 (2015) 186191.

[53] X. Wang, A. Raghavan, T. Chen, L. Qiao, Y. Zhang, Q. Ding, K. Musunuru, CRISPR-Cas9 Targeting of PCSK9 in Human Hepatocytes In Vivo-Brief Report, Arterioscler. Thromb. Vasc. Biol. 36 (2016) 783-786.

[54] C. Jiang, M. Mei, B. Li, X. Zhu, W. Zu, Y. Tian, Q. Wang, Y. Guo, Y. Dong, X. Tan, A non-viral CRISPR/Cas9 delivery system for therapeutically targeting HBV DNA and pcsk9 in vivo, Cell Res. 27 (2017) 440-443.

[55] A. King, A CRISPR edit for heart disease, Nature 555 (2018) S23-S25.

[56] M.D. Disney, Inhibiting Translation One Protein at a Time, Trends Biochem. Sci. 42 (2017) $412-$ 413.

[57] D.N. Petersen, J. Hawkins, W. Ruangsiriluk, K.A. Stevens, B.A. Maguire, T.N. O’Connell, B.N. Rocke, M. Boehm, R.B. Ruggeri, T. Rolph, A small-molecule anti-secretagogue of PCSK9 targets the 80S ribosome to inhibit PCSK9 protein translation, Cell Chem. Biol. 23 (2016) 1362-1371.

[58] E. Darout, R. Dullea, L. Hawkins, A.T. Londregan, P.M. Loria, B. Maguire, K.F. Mcclure, D.N. Petersen, D.W. Piotrowski, N-piperidin-3-ylbenzamide derivatives for treating cardiovascular diseases, WO 2014/170786 A1, 23 October, 2014.

[59] N.G. Lintner, K.F. McClure, D. Petersen, A.T. Londregan, D.W. Piotrowski, L. Wei, J. Xiao, M. Bolt, P.M. Loria, B. Maguire, Selective stalling of human translation through small-molecule engagement of the ribosome nascent chain, PLoS Biol. 15 (2017) e2001882.

[60] M.A. Ortega, W.A. Van Der Donk, New insights into the biosynthetic logic of ribosomally synthesized and post-translationally modified peptide natural products, Cell Chem. Biol. 23 (2016) 3144. 
[61] W. Wang, S. Nag, X. Zhang, M.H. Wang, H. Wang, J. Zhou, R. Zhang, Ribosomal proteins and human diseases: pathogenesis, molecular mechanisms, and therapeutic implications, Med. Res. Rev. 35 (2015) 225-285.

[62] K.F. McClure, D.W. Piotrowski, D. Petersen, L. Wei, J. Xiao, A.T. Londregan, A.S. Kamlet, A.M. Dechert-Schmitt, B. Raymer, R.B. Ruggeri, Liver-Targeted Small-Molecule Inhibitors of Proprotein Convertase Subtilisin/Kexin Type 9 Synthesis, Angew. Chem. Int. Ed. Engl. 56 (2017) 16218-16222.

[63] E, Darout. K.F. Mcclure, D. Piotrowski, B. Raymer, Substituted amide compounds, WO 2016/055901 A1, 14 April, 2016.

[64] J.A. Pfefferkorn, Strategies for the design of hepatoselective glucokinase activators to treat type 2 diabetes, Expert Opin. Drug Discov. 8 (2013) 319-330.

[65] M. Takahashi, T. Ogawa, H. Kashiwagi, F. Fukushima, M. Yoshitsugu, M. Haba, M. Hosokawa, Chemical synthesis of an indomethacin ester prodrug and its metabolic activation by human carboxylesterase 1, Bioorg. Med. Chem. Lett. 28 (2018) 997-1000.

[66] A.T. Londregan, L. Wei, J. Xiao, N.G. Lintner, D. Petersen, R.G. Dullea, K.F. McClure, M.W. Bolt, J.S. Warmus, S.B. Coffey, C. Limberakis, J. Genovino, B.A. Thuma, K.D. Hesp, G.E. Aspnes, B. Reidich, C.T. Salatto, J.R. Chabot, J.H.D. Cate, S. Liras, D.W. Piotrowski, Small Molecule Proprotein Convertase Subtilisin/Kexin Type 9 (PCSK9) Inhibitors: Hit to Lead Optimization of Systemic Agents, J. Med. Chem. 61 (2018) 5704-5718

[67] A. Yonath, Antibiotics targeting ribosomes: resistance, selectivity, synergism, and cellular regulation, Annu. Rev. Biochem. 74 (2005) 649-679.

[68] D. Cunningham, D.E. Danley, K.F. Geoghegan, M.C. Griffor, J.L. Hawkins, T.A. Subashi, A.H. Varghese, M.J. Ammirati, J.S. Culp, L.R. Hoth, Structural and biophysical studies of PCSK9 and its mutants linked to familial hypercholesterolemia, Nat. Struct. Mol. Biol. 14 (2007) 413-419.

[69] C. Gustafsen, D. Olsen, J. Vilstrup, S. Lund, A. Reinhardt, N. Wellner, T. Larsen, C.B. Andersen, K. Weyer, J.-p. Li, Heparan sulfate proteoglycans present PCSK9 to the LDL receptor, Nat. Commun. 8 (2017) 503 .

[70] G. Cassinelli, N. Zaffaroni, C. Lanzi, The heparanase/heparan sulfate proteoglycan axis: A potential new therapeutic target in sarcomas, Cancer Lett. 382 (2016) 245-254.

[71] A. Shulman, Heparin for prevention of atherosclerosis, N. Engl. J. Med. 319 (1988) 1154-1155. 
[72] G.N. Serneri, G. Gensini, M. Carnovali, F. Rovelli, S. Pirelli, A. Fortini, Effectiveness of low-dose heparin in prevention of myocardial reinfarction, Lancet 329 (1987) 937-942.

[73] H. Engelberg, R. Kuhn, M. Steinman, A controlled study of the effect of intermittent heparin therapy on the course of human coronary atherosclerosis, Circulation 13 (1956) 489-498.

[74] L. Böttiger, L. Carlson, L. Engstedt, L. Orö, Long-term Heparin Treatment in Ischaemic Heart Disease, J. Intern. Med. 182 (1967) 245-257.

[75] J. Sayen, R. Singer, G. Peirce, O. Horwitz, Unstable angina, myocardial infarction, heparin and death: medium dose heparin (not exceeding 20,000 units/day) in the treatment of patients with acute coronary event-first year and long-term comparative mortality, Trans. Am. Clin. Climatol. Assoc. 94 (1983) 141-153.

[76] X. Yang, J. Zhang, L. Chen, Q. Wu, C. Yu, Chitosan oligosaccharides enhance lipid droplets via down-regulation of PCSK9 gene expression in HepG2 cells, Exp. Cell Res. 366 (2018) 152-160.

[77] D.-K. Min, H.-S. Lee, N. Lee, C.J. Lee, H.J. Song, G.E. Yang, D. Yoon, S.W. Park, In silico Screening of Chemical Libraries to Develop Inhibitors That Hamper the Interaction of PCSK9 with the LDL Receptor, Yonsei Med. J. 56 (2015) 1251-1257.

[78] S.W. Park, H.S. Lee, D.K. Min, N.R. Lee, C.J. Lee, G.E. Yang, Composition for preventing and treating cholesterol-related diseases, WO 2016/108572 A2, 07 July, 2016.

[79] R.H. Alghamdi, P. O'Reilly, C. Lu, J. Gomes, T.A. Lagace, A. Basak, LDL-R promoting activity of peptides derived from human PCSK9 catalytic domain (153-421): design, synthesis and biochemical evaluation, Eur. J. Med. Chem. 92 (2015) 890-907.

[80] M. Pelay-Gimeno, A. Glas, O. Koch, T.N. Grossmann, Structure-Based Design of Inhibitors of Protein-Protein Interactions: Mimicking Peptide Binding Epitopes, Angew. Chem. Int. Ed. Engl. 54 (2015) 8896-8927.

[81] P.L. Surdo, M.J. Bottomley, A. Calzetta, E.C. Settembre, A. Cirillo, S. Pandit, Y.G. Ni, B. Hubbard, A. Sitlani, A. Carfí, Mechanistic implications for LDL receptor degradation from the PCSK9/LDLR structure at neutral pH, EMBO Rep. 12 (2011) 1300-1305.

[82] M. Stucchi, G. Grazioso, C. Lammi, S. Manara, C. Zanoni, A. Arnoldi, G. Lesma, A. Silvani, Disrupting the PCSK9/LDLR protein-protein interaction by an imidazole-based minimalist peptidomimetic, Org. Biomol. Chem. 14 (2016) 9736-9740. 
[83] E. Ko, J. Liu, L.M. Perez, G. Lu, A. Schaefer, K. Burgess, Universal peptidomimetics, J. Am. Chem. Soc. 133 (2010) 462-477.

[84] J. Taechalertpaisarn, B. Zhao, X. Liang, K. Burgess, Small Molecule Inhibitors of the PCSK9. LDLR Interaction, J. Am. Chem. Soc. 140 (2018) 3242-3249.

[85] E. Ko, A. Raghuraman, L.M. Perez, T.R. Ioerger, K. Burgess, Exploring key orientations at proteinprotein interfaces with small molecule probes, J. Am. Chem. Soc. 135 (2012) 167-173.

[86] D. Xin, A. Holzenburg, K. Burgess, Small molecule probes that perturb a protein-protein interface in antithrombin, Chem. Sci. 5 (2014) 4914-4921.

[87] A. Sahebkar, M.-C. Serban, A. Gluba-Brzózka, D.P. Mikhailidis, A.F. Cicero, J. Rysz, M. Banach, Lipid-modifying effects of nutraceuticals: An evidence-based approach, Nutrition 32 (2016) 1179-1192. [88] Y. Rao, H. Liu, L. Gao, H. Yu, T.-M. Ou, J.-H. Tan, S.-L. Huang, H.-G. Wang, D. Li, L.-Q. Gu, Synthesis and biological evaluation of novel Bouchardatine derivatives as Potential Adipogenesis/lipogenesis inhibitors for Antiobesity treatment, J. Med. Chem. 58 (2015) 9395-9413.

[89] A.A. Momtazi, M. Banach, M. Pirro, N. Katsiki, A. Sahebkar, Regulation of PCSK9 by nutraceuticals, Pharm. Res. 120 (2017) 157-169.

[90] S.P. Singh, K.V. Sashidhara, Lipid lowering agents of natural origin: An account of some promising chemotypes, Eur. J. Med. Chem. 140 (2017) 331-348.

[91] M. Imanshahidi, H. Hosseinzadeh, Pharmacological and therapeutic effects of Berberis vulgaris and its active constituent, berberine, Phytother. Res. 22 (2008) 999-1012.

[92] W.-J. Kong, J. Wei, Z.-Y. Zuo, Y.-M. Wang, D.-Q. Song, X.-F. You, L.-X. Zhao, H.-N. Pan, J.-D. Jiang, Combination of simvastatin with berberine improves the lipid-lowering efficacy, Metabolism. 57 (2008) 1029-1037.

[93] H. Dong, Y. Zhao, L. Zhao, F. Lu, The effects of berberine on blood lipids: a systemic review and meta-analysis of randomized controlled trials, Planta Med. 79 (2013) 437-446.

[94] W. Kong, J. Wei, P. Abidi, M. Lin, S. Inaba, C. Li, Y. Wang, Z. Wang, S. Si, H. Pan, Berberine is a novel cholesterol-lowering drug working through a unique mechanism distinct from statins, Nat. Med. 10 (2004) 1344-1351.

[95] J. Cameron, T. Ranheim, M.A. Kulseth, T.P. Leren, K.E. Berge, Berberine decreases PCSK9 expression in HepG2 cells, Atherosclerosis 201 (2008) 266-273. 
[96] H. Li, B. Dong, S.W. Park, H.-S. Lee, W. Chen, J. Liu, Hepatocyte nuclear factor $1 \alpha$ plays a critical role in PCSK9 gene transcription and regulation by the natural hypocholesterolemic compound berberine, J. Biol. Chem. 284 (2009) 28885-28895.

[97] H.-T. Xiao, J. Peng, Y. Liang, J. Yang, X. Bai, X.-Y. Hao, F.-M. Yang, Q.-Y. Sun, Acetylcholinesterase inhibitors from Corydalis yanhusuo, Nat. Prod. Res. 25 (2011) 1418-1422.

[98] A. Adsersen, A. Kjølbye, O. Dall, A.K. Jäger, Acetylcholinesterase and butyrylcholinesterase inhibitory compounds from Corydalis cava Schweigg. \& Kort, J. Ethnopharmacol. 113 (2007) 179-182. [99] H.-Q. Wang, J. Hu, H.-Y. Yan, S. Wu, Y.-H. Li, Corydaline inhibits enterovirus 71 replication by regulating COX-2 expression, J. Asian Nat. Prod. Res. 19 (2017) 1124-1133.

[100] Q. Zhang, C. Chen, F.-Q. Wang, C.-H. Li, Q.-H. Zhang, Y.-J. Hu, Z.-N. Xia, F.-Q. Yang, Simultaneous screening and analysis of antiplatelet aggregation active alkaloids from Rhizoma Corydalis, Pharm. Biol. 54 (2016) 3113-3120.

[101] J. Han, S. Shim, K. Jang, Y. Choi, H. Kim, G. Choi, In vivo disease control efficacy of isoquinoline alkaloids isolated from Corydalis ternata against wheat leaf rust and pepper anthracnose, J. Microbiol. Biotechnol, 28 (2017) 262-266.

[102] H.Y. Liu, G.P. Li, J.B. Wang, J.W. Liu, Berberine derivatives useful for modulating lipid levels and their methods of synthesis, WO2011/006000 A1, 13 January, 2011.

[103] H.Y. Liu, G.P. Li, Wang, J.W. Liu, Carydaline derivatives useful for reducing lipid levels, WO2010/075469 A1, 01 July, 2010.

[104] http://www.chinadrugtrials.org.cn/ No. CTR20160744

[105] H. Liu, Y.P. Wang, F. Zhao, J. Zhao, J. Wang, C. Xi, C.L. Wu, H. Shen, X. Han, H.L. Jiang, K.X. Chen, Phenyl [a]indole[2,3-g]quinolizine compounds, preparation method therefor, pharmaceutical composition, and applications thereof, WO 2017/167202 A1, 29 March, 2017.

[106] C.E. Green, S.L. Hibbert, Y.A. Bailey-Shaw, L.A. Williams, S. Mitchell, E. Garraway, Extraction, processing, and storage effects on curcuminoids and oleoresin yields from Curcuma longa L. grown in Jamaica, J. Agric. Food. Chem. 56 (2008) 3664-3670.

[107] A.B. Kunnumakkara, D. Bordoloi, G. Padmavathi, J. Monisha, N.K. Roy, S. Prasad, B.B. Aggarwal, Curcumin, the golden nutraceutical: multitargeting for multiple chronic diseases, Brit. J. Pharmacol. 174 (2017) 1325-1348. 
[108] Y.S. Yang, Y.F. Su, H.W. Yang, Y.H. Lee, J.I. Chou, K.C. Ueng, Lipid-Lowering Effects of Curcumin in Patients with Metabolic Syndrome: A Randomized, Double-Blind, Placebo-Controlled Trial, Phytother. Res. 28 (2014) 1770-1777.

[109] P. Neerati, R. Devde, A.K. Gangi, Evaluation of the Effect of Curcumin Capsules on Glyburide Therapy in Patients with Type-2 Diabetes Mellitus, Phytother. Res. 28 (2014) 1796-1800.

[110] Z.C. Ping, S.S. Wei, G.Y. Zhen, O. Lu, L.L. Mei, Z. Xing, T.Q. Hui, L.X. Yong, L.D. Fang, PCSK9/LDLR pathway mediates curcumin trinicotinate promoting lipid uptake of HepG2, Prog. Biochem. Biophys. 42 (2015) 825-832.

[111] K.M. Nelson, J.L. Dahlin, J. Bisson, J. Graham, G.F. Pauli, M.A. Walters, The essential medicinal chemistry of curcumin: miniperspective, J. Med. Chem. 60 (2017) 1620-1637.

[112] M. Saleem, H.J. Kim, M.S. Ali, Y.S. Lee, An update on bioactive plant lignans, Nat. Prod. Rep. 22 (2005) 696-716.

[113] P. Pel, H.-S. Chae, P. Nhoek, W. Yeo, Y.-M. Kim, Y.-W. Chin, Lignans from the fruits of Schisandra chinensis (Turcz.) Baill inhibit proprotein convertase subtilisin/kexin type 9 expression, Phytochemistry 136 (2017) 119-124.

[114] M.P. Adorni, N. Ferri, S. Marchianò, V. Trimarco, F. Rozza, R. Izzo, F. Bernini, F. Zimetti, Effect of a novel nutraceutical combination on serum lipoprotein functional profile and circulating PCSK9, Ther. Clin. Risk Manag. 13 (2017) 1555-1562.

[115] Q. Yuan, L. Zhao, The Mulberry (Morus alba L.) Fruit A Review of Characteristic Components and Health Benefits, J. Agric. Food. Chem. 65 (2017) 10383-10394.

[116] P. Pel, H.-S. Chae, P. Nhoek, Y.-M. Kim, Y.-W. Chin, Chemical constituents with proprotein convertase subtilisin/kexin type 9 mRNA expression inhibitory activity from dried immature Morus alba fruits, J. Agric. Food. Chem. 65 (2017) 5316-5321.

[117] J. Hao, C. Chen, K. Huang, J. Huang, J. Li, P. Liu, H. Huang, Polydatin improves glucose and lipid metabolism in experimental diabetes through activating the Akt signaling pathway, Eur. J. Pharmacol. 745 (2014) 152-165.

[118] Y. Wang, J. Ye, J. Li, C. Chen, J. Huang, P. Liu, H. Huang, Polydatin ameliorates lipid and glucose metabolism in type 2 diabetes mellitus by downregulating proprotein convertase subtilisin/kexin type 9 (PCSK9), Cardiovasc. Diabetol. 15 (2016) 19. 
[119] S. Gao, Z. Liu, H. Li, P.J. Little, P. Liu, S. Xu, Cardiovascular actions and therapeutic potential of tanshinone IIA, Atherosclerosis 220 (2012) 3-10.

[120] H.-C. Chen, P.-Y. Chen, M.-J. Wu, M.-H. Tai, J.-H. Yen, Tanshinone IIA modulates low density lipoprotein uptake via down-regulation of PCSK9 gene expression in HepG2 Cells, PloS one, 11 (2016) e0162414.

[121] L. Jia, N. Song, G. Yang, Y. Ma, X. Li, R. Lu, H. Cao, N. Zhang, M. Zhu, J. Wang, Effects of Tanshinone IIA on the modulation of miR-33a and the SREBP-2/Pcsk9 signaling pathway in hyperlipidemic rats, Mol. Med. Rep. 13 (2016) 4627-4635.

[122] K. Yamamoto, T. Kimura, A. Sugitachi, N. Matsuura, Anti-angiogenic and anti-metastatic effects of $\beta$-1, 3-D-glucan purified from Hanabiratake, Sparassis crispa, Biol. Pharm. Bull. 32 (2009) 259-263.

[123] S. Bang, H.-S. Chae, C. Lee, H.G. Choi, J. Ryu, W. Li, H. Lee, G.-S. Jeong, Y.-W. Chin, S.H. Shim, New Aromatic Compounds from the Fruiting Body of Sparassis crispa (Wulf.) and Their Inhibitory Activities on Proprotein Convertase Subtilisin/Kexin Type 9 mRNA Expression, J. Agric. Food. Chem. 65 (2017) 6152-6157.

[124] P. Nhoek, H.-S. Chae, J.N. Masagalli, K. Mailar, P. Pel, Y.-M. Kim, W.J. Choi, Y.-W. Chin, Discovery of Flavonoids from Scutellaria baicalensis with Inhibitory Activity Against PCSK 9 Expression: Isolation, Synthesis and Their Biological Evaluation, Molecules. 23 (2018) 504.

[125] Y. Li, J. Yao, C. Han, J. Yang, M.T. Chaudhry, S. Wang, H. Liu, Y. Yin, Quercetin, inflammation and immunity, Nutrients 8 (2016) 167.

[126] R.V. Patel, B.M. Mistry, S.K. Shinde, R. Syed, V. Singh, H.S. Shin, Therapeutic potential of quercetin as a cardiovascular agent, Eur. J. Med. Chem. 155 (2018) 889-904.

[127] M. Mbikay, F. Sirois, S. Simoes, J. Mayne, M. Chrétien, Quercetin-3-glucoside increases lowdensity lipoprotein receptor (LDLR) expression, attenuates proprotein convertase subtilisin/kexin 9 (PCSK9) secretion, and stimulates LDL uptake by Huh7 human hepatocytes in culture, FEBS Open Bio. 4 (2014) 755-762.

[128] W.Y. Gao, P.Y. Chen, S.F. Chen, M.J. Wu, H.Y. Chang, J.H. Yen, Pinostrobin Inhibits Proprotein Convertase Subtilisin/Kexin-type 9 (PCSK9) Gene Expression through the Modulation of FoxO3a Protein in HepG2 Cells, J. Agric. Food Chem. 66 (2018) 6083-6093. 
[129] G.G. Sui, H.B. Xiao, X.Y. Lu, Z.L. Sun, Naringin activates AMPK resulting in altered expression of SREBPs, PCSK9, and LDLR to reduce body weight in obese C57BL/6J mice, J. Agric. Food Chem. (2018) doi: 10.1021/acs.jafc.8b02696.

[130] S.C. Chong, M.A. Dollah, P.P. Chong, A. Maha, Phaleria macrocarpa (Scheff.) Boerl fruit aqueous extract enhances LDL receptor and PCSK9 expression in vivo and in vitro, J. Ethnopharmacol. 137 (2011) $817-827$

[131] Y. Zhang, J. Liu, S. Li, R.-X. Xu, J. Sun, J.-J. Li, Impact of currently prescribed lipid-lowering drugs on plasma PCSK9 concentration: single or in combination study in rats, Lipids Health Dis. 13 (2014) 35 .

[132] Y.J. Jia, Y. Zhang, J. Liu, Y.L. Guo, R.X. Xu, J.J. Li, Short-and long-term effects of Xuezhikang (血脂康), an extract of cholestin, on serum proprotein convertase subtilisin/kexin type 9 levels, Chin. J. Integr. Med. 22 (2016) 96-100.

[133] Y.C. Ong, Z. Aziz, Systematic review of red yeast rice compared with simvastatin in dyslipidaemia, J. Clin. Pharm. Ther. 41 (2016) 170-179.

[134] C.B. Graversen, S. Lundbye-Christensen, B. Thomsen, J.H. Christensen, E.B. Schmidt, Marine n3 polyunsaturated fatty acids lower plasma proprotein convertase subtilisin kexin type 9 levels in preand postmenopausal women: a randomised study, Vasc. Pharmacol. 76 (2016) 37-41.

[135] S. Elbitar, P.E. Khoury, Y. Ghaleb, J.-P. Rabès, M. Varret, N.G. Seidah, C. Boileau, M. Abifadel, Proprotein convertase subtilisin/kexin 9 (PCSK9) inhibitors and the future of dyslipidemia therapy: an updated patent review (2011-2015), Expert Opin. Ther. Pat. 26 (2016) 1377-1392.

[136] T.E. Barta, J.W. Bourne, K.D. Monroe, M.M. Muehlemann, A. Pandey, S. Bowers, Composition and methods of use of tetrahydroisoquinoline small molecules to bind and modulate PCSK9 protein activity, WO 2017/034990 A1, 02 March, 2017.

[137] T.E. Barta, J.W. Bourne, K.D. Monroe, M.M. Muehlemann, A. Pandey, S Bowers, Composition and methods of use of novel phenylalanine small organic compounds to directly modulate PCSK9 protein activity, WO 2017/034994 A1, 02 March, 2017.

[138] T.E. Barta, J.W. Bourne, K.D. Monroe, M.M. Muehlemann, A. Pandey, S. Bowers, Phenylpiperazine proprotein convertase subtilisin/kexin type 9 (PCSK9) modulators and their use, WO 2017/034997 A1, 02 March, 2017. 
[139] S.S. Abdel-Meguid, N. Elshourbagy, H. Meyers, S.A. Mousa, Anti-proprotein convertase subtilisin kexin type 9 (anti-PCSK9) compounds and methods of using the same in the treatment and/or prevention of cardiovascular diseases, WO 2014/150326 A1, 25 September, 2014.

[140] S.S. Abdel-Meguid, M. Abou-Gharbia, B. Blass, W. Childers, N. Elshourbagy, V. Ghidu, R. Martinez, H. Meyers, S.A. Mousa, Anti-PCSK9 compounds and methods for the treatment and/or prevention of cardiovascular diseases, WO 2014/150395 A1, 25 September, 2014.

[141] S.S. Abdel-Meguid, N.A. Elshourbagy, H.V. Meyers, S.A. Mousa, Anti-proprotein convertase subtilisin kexin type 9 (anti-PCSK9) compounds and methods of using the same in the treatment and/or prevention of cardiovascular diseases, WO 2017/222953 A1, 28 December, 2017.

[142] M. Abou-Gharbia, W.E. Childers, PCSK9 inhibitors and methods of use thereof, WO 2016/040305 A1, 17 March, 2016.

[143] M.M. Muehlemann, T.E. Barta, K.D. Monroe, J.W. Bourne, M.T. Reece, V. Nevalainen, Proprotein convertase subtilisin/kexin type 9 (PCSK9) allosteric binding ligands to modulate serum low density lipoprotein (LDL) levels, WO 2014/127316 A2, 21 August, 2014.

[144] T.E. Barta, J.W. Bourne, K.D. Monroe, M.M. Muehlemann, Composition and methods of use of small molecules as binding ligands for the modulation of proprotein convertase subtilisin/kexin type 9 (PCSK9) protein activity, WO 2016/029037 A1, 25 February, 2016.

[145] M.R. Arkin, Y. Tang, J.A. Wells, Small-molecule inhibitors of protein-protein interactions: progressing toward the reality, Chem. Biol. 21 (2014) 1102-1114.

[146] R. Scharfmann, L. Huijbregts, Methods and compositions for reducing PCSK9 expression, WO 2018/024878 A1, 08 February, 2018.

[147] J.C. Milne, M.R. Jirousek, C.B. Vu, Methods of lowering proprotein convertase subtilisin/kexin type 9 (PCSK9), WO 2013/177536 A2, 28 November, 2013.

[148] M.R. Jirousek, J.C. Milne, C.B. Vu, Fatty acid niacin conjugates, WO 2015/073901 A1, 21 May, 2015.

[149] C.B. Vu, J.E. Bemis, E. Benson, P. Bista, D. Carney, R. Fahrner, D. Lee, F. Liu, P. Lonkar, J.C. Milne, Synthesis and characterization of fatty acid conjugates of niacin and salicylic acid, J. Med. Chem. 59 (2016) 1217-1231.

[150] D.Q. Li, Substituted nitrogen-containing heterocyclic derivatives and applications thereof, WO 2016/107603 A1, 07 July, 2016. 
[151] D.Q. Li, Substituted nitrogen heterocyclic derivatives and use thereof, WO 2016/107602 A1, 07 July, 2016.

[152] M.M. Nagiec, J.R. Perez, M. Palmer, J. Duvall, A. Skepner, E. Comer, Modulators of hepatic lipoprotein metabolism, WO 2014/028946 A2, 20 February, 2014.

[153] M. Nagiec, J. Perez, J. Duvall, M. Palmer, A.P. Skepner, Modulators of hepatic lipoprotein metabolism, WO 2016/100711 A1, 23 June, 2016.

[154] D. Guay, S. Crane, N. Lachance, J. Chiasson, V.L. Truong, P. Lacombe, K. Skorey, N.G. Seidah, Small molecule modulators of PCSK9 and methods of use thereof, WO 2014/139008 A1, 18 September, 2014.

[155] A.C. Li, E. Yu, S.C. Ring, J.P. Chovan, Boronic Acid-Containing Proteasome Inhibitors: Alert to Potential Pharmaceutical Bioactivation, Chem. Res. Toxicol. 26 (2013) 608-615.

[156] H. Pingali, S. Kalapatapu, P. Makadia, M.R. Jain, Compounds for the treatment of dyslipidemia and related diseases, WO 2011/051961 A1, 05 May, 2011.

[157] H. Pingali, P. Makadia, V. Pandya, S. Kalapatapu, M.R. Jain, Heterocyclic compounds suitable for the treatment of dyslipidemia, WO 2012/090220 A1, 05 July, 2012.

[158] H. Pingali, P. Makadia, V. Pandya, S. Kalapatapu, Novel compounds for the treatment of dyslipidemia and related diseases, WO 2013/132509 A1, 12 March, 2013.

[159] H. Pingali, V. Pandya, Compounds for the treatment of dyslipidemia and other diseases, WO 2014/002105 A1, 03 January, 2014.

[160] H. Pingali, V. Pandya, Novel compounds for the treatment of dyslipidemia and related diseases, WO 2014/002106 A1, 03 January, 2014.

[161] J.E. Imbriglio, W.L. Petrilli, Y.S. Xiong, Z. Feng, H. Youm, W. Chang, R. Liang, Z.J. Lu, J.A. Jerry, S.B. Hoyt, Substituted 1-methyl-1,2,3,4-tetrahydroisoquinoline molecules as PCSK9 allosteric binders, WO2018/057409 A1, 29 February, 2018.

[162] Y. Zhang, M. Ultsch, N.J. Skelton, D.J. Burdick, M.H. Beresini, W. Li, M. Kong-Beltran, A. Peterson, J. Quinn, C. Chiu, Y. Wu, S. Shia, P. Moran, P. Di Lello, C. Eigenbrot, D. Kirchhofer, Discovery of a cryptic peptide-binding site on PCSK9 and design of antagonists, Nat. Struct. Mol. Biol. 24 (2017) 848-856.

[163] A. Ashkenazi, W.J. Fairbrother, J.D. Leverson, A.J. Souers, From basic apoptosis discoveries to advanced selective BCL-2 family inhibitors, Nat. Rev. Drug Discov. 16 (2017) 273-284. 
[164] J. Zhou, J. Rossi, Aptamers as targeted therapeutics: current potential and challenges, Nat. Rev. Drug Discov. 16 (2017) 181-202

[165] B.N. Gawande, J.C. Rohloff, J.D. Carter, I. von Carlowitz, C. Zhang, D.J. Schneider, N. Janjic, Selection of DNA aptamers with two modified bases, Proc. Natl. Acad. Sci. U. S. A. 114 (2017) 28982903.

[166] Z. Chen, P.A. Lichtor, A.P. Berliner, J.C. Chen, D.R. Liu, Evolution of sequence-defined highly functionalized nucleic acid polymers, Nat. Chem. 10 (2018) 420-427

[167] Z. Zhao, Y. Tuakli-Wosornu, T.A. Lagace, L. Kinch, N.V. Grishin, J.D. Horton, J.C. Cohen, H.H. Hobbs, Molecular characterization of loss-of-function mutations in PCSK9 and identification of a compound heterozygote, Am. J. Hum. Genet. 79 (2006) 514-523.

[168] D.P. Bondeson, A. Mares, I.E. Smith, E. Ko, S. Campos, A.H. Miah, K.E. Mulholland, N. Routly, D.L. Buckley, J.L. Gustafson, Catalytic in vivo protein knockdown by small-molecule PROTACs, Nat. Chem. Biol. 11 (2015) 611.

[169] G. Dubuc, A. Chamberland, H. Wassef, J. Davignon, N.G. Seidah, L. Bernier, A. Prat, Statins upregulate PCSK9, the gene encoding the proprotein convertase neural apoptosis-regulated convertase1 implicated in familial hypercholesterolemia, Arterioscler. Thromb. Vasc. Biol. 24 (2004) 1454-1459. [170] K. Miyosawa, Y. Watanabe, K. Murakami, T. Murakami, H. Shibata, M. Iwashita, H. Yamazaki, K. Yamazaki, T. Ohgiya, K. Shibuya, New CETP inhibitor K-312 reduces PCSK9 expression: a potential effect on LDL cholesterol metabolism, Am. J. Physiol. Endocrinol. Metab. 309 (2015) E177-E190.

[171] S. Poirier, M. Mamarbachi, W.-T. Chen, A.S. Lee, G. Mayer, GRP94 regulates circulating cholesterol levels through blockade of PCSK9-induced LDLR degradation, Cell Rep. 13 (2015) 20642071.

[172] A. Arrieta, T.F. Page, E. Veledar, K. Nasir, Economic evaluation of PCSK9 inhibitors in reducing cardiovascular risk from health system and private payer perspectives, PloS one, 12 (2017) e0169761. [173] M.C. Stam-Slob, Y. van der Graaf, A. de Boer, J.P. Greving, F.L. Visseren, Cost-effectiveness of PCSK9 inhibition in addition to standard lipid-lowering therapy in patients at high risk for vascular disease, Int. J. Cardiol. 253 (2018) 148-154.

[174] S.J. Baum, C.P. Cannon, PCSK9 inhibitor valuation: A science-based review of the two recent models, Clin. Cardiol. 41 (2018) 544-550. 
[175] T. Kosenko, M. Golder, G. Leblond, W. Weng, T.A. Lagace, Low density lipoprotein binds to proprotein convertase subtilisin/kexin type-9 (PCSK9) in human plasma and inhibits PCSK9-mediated low density lipoprotein receptor degradation, J. Biol. Chem. 288 (2013) 8279-8288.

[176] D.E. Scott, A.R. Bayly, C. Abell, J. Skidmore, Small molecules, big targets: drug discovery faces the protein-protein interaction challenge, Nat. Rev. Drug Discov. 15 (2016) 533. 